\title{
Improved Thermo-Physical Properties and Energy Efficiency of Hybrid PCM/Graphene-Silver nanocomposite in a hybrid CPV/Thermal Solar System
}

\author{
Navid Aslfattahi, ${ }^{1, *}$, R. Saidur ${ }^{2,4, *}$, A. Arifutzzaman ${ }^{2}$, AS Abdelrazik ${ }^{3}$, L \\ Samylingam ${ }^{2}$, Mohd Faizul Mohd Sabri ${ }^{1, *}$, Nor Azwadi Che Sidik ${ }^{5}$ \\ ${ }^{1}$ Department of Mechanical Engineering, Faculty of Engineering, University of Malaya, 50603, Kuala Lumpur, \\ Malaysia \\ ${ }^{2}$ Research Center for Nano-Materials and Energy Technology (RCNMET), School of Science and Technology, \\ Sunway University, Bandar Sunway, Petaling Jaya, 47500, Selangor Darul Ehsan, Malaysia \\ ${ }^{3}$ Mechanical Engineering Department, King Fahd University of Petroleum \& Minerals, Dhahran, Saudi Arabia \\ ${ }^{4}$ Department of Engineering, Lancaster University, Lancaster, LAl 4YW, UK \\ ${ }^{5}$ Malaysia - Japan International Institute of Technology (MJIIT), University Teknologi Malaysia, Jalan Sultan \\ Yahya Petra,54100 Kuala Lumpur, Malaysia
}

Corresponding authors: Navid.fth87@yahoo.com, Saidur@sunway.edu.my, Faizul@um.edu.my

\begin{abstract}
In this research work, novel hybrid Graphene-Silver (Gr-Ag) nanomaterial has been used for first time with paraffin wax as a phase change material (PCM) to improve its thermo-physical properties. Thermal and electrical energy efficiencies of the novel synthesized nanocomposite (PCM/Graphene-Silver) has been investigated in solar thermal collector systems (CPV/T). This paper focuses on preparation, characterization, thermo-physical properties and energy efficiency in concentrated photovoltaic/thermal (CPV/T) system of new class of nanocomposites induced with hybrid Gr-Ag nanomaterial in three different concentrations. The specific heat capacity $\left(c_{\mathrm{p}}\right)$ of hybrid PCM/Graphene-Silver nanocomposite increased by introducing hybrid Gr-Ag nanomaterial. Electrical and thermal energy performance of the hybrid PCM/Graphene-Silver is investigated in a CPV/T system using Matlab 2017b program. The improvement of $c_{\mathrm{p}}$ is found to be $\sim 40 \%$ with 0.3 mass\% of hybrid Gr-Ag nanomaterial loaded in PCM. The highest thermal conductivity increment is found to be $\sim 11 \%$ at 0.3 mass\% concentration of hybrid $\mathrm{Gr}-\mathrm{Ag}$ nanomaterial in PCM. The endothermic enthalpy value of the hybrid PCM/Graphene-Silver nanocomposite is found to be $\sim 75.6 \mathrm{~J} \mathrm{~g}^{-1}$ at 0.1 mass\% loading concentration of hybrid $\mathrm{Gr}-\mathrm{Ag}$
\end{abstract}


nanomaterial. Melting point of hybrid PCM/Graphene-Silver nanocomposite with loading concentration of 0.3 mass $\%$ is measured to be $73.2{ }^{\circ} \mathrm{C}$. The highest thermal efficiency using the hybrid Graphene-silver nanoparticles reached the value of $39.62 \%$ which represents $4.16 \%$ increment in comparison with the pure PCM. The equivalent electrical efficiency is improved by $2.8 \%$ at the loading concentration of 0.3 mass $\%$ of the hybrid Gr-Ag nanomaterial. These new class of nanocomposites represented the capability of enhancement in the performance of the $\mathrm{CPV} / \mathrm{T}$ system consisting of lower PV temperatures, higher temperature gains across the cooling fluid and higher electrical and thermal efficiencies.

Keywords. hybrid nanocomposite; energy efficiency; CPV/T, thermal storage

\begin{tabular}{|c|c|c|c|}
\hline \multicolumn{4}{|l|}{ Nomenclature } \\
\hline \multicolumn{4}{|l|}{ Symbols } \\
\hline $\mathrm{T}$ & temperature, ${ }^{\circ} \mathrm{C}$ & $\mathrm{G}$ & solar radiation, $\mathrm{W} \mathrm{m} \mathrm{m}^{-2}$ \\
\hline $\mathrm{L}$ & length of PV/T system, m & $\mathrm{h}$ & Heat transfer coefficient, $\mathrm{W} \mathrm{m} \mathrm{m}^{-2} \mathrm{~K}^{-1}$ \\
\hline $\mathrm{W}$ & width of PV/T system, m & $\mathrm{k}$ & Thermal conductivity, $\mathrm{W} \mathrm{m}^{-1} \mathrm{~K}^{-1}$ \\
\hline $\mathrm{t}$ & height, mm & $\Delta \mathrm{x}$ & Spatial step, m \\
\hline $\mathrm{m}$ & mass, $\mathrm{kg}$ & $\Delta \mathrm{t}$ & Time step, sec \\
\hline $\mathrm{m} \cdot$ & mass flow rate, $\mathrm{kg} \mathrm{s}^{-1}$ & $\mathrm{v}$ & velocity, $\mathrm{m} \mathrm{s}^{-1}$ \\
\hline$c_{\mathrm{p}}$ & Specific heat, $\mathrm{J} \mathrm{g}^{-1} \mathrm{~K}^{-1}$ & $\mathrm{C}$ & solar concentration \\
\hline $\mathrm{E}$ & energy, J & & \\
\hline \multicolumn{4}{|l|}{ Greek symbols } \\
\hline$\alpha$ & absorptance & $\eta$ & efficiency \\
\hline$\beta$ & temperature coefficient, $\mathrm{K}^{-1}$ & $\phi_{\mathrm{w}}$ & mass fraction \\
\hline$\varepsilon$ & emissivity & & \\
\hline \multicolumn{4}{|l|}{ Subscripts } \\
\hline $\mathrm{amb}$ & ambient & elec & electrical \\
\hline npcm & nanoPCM & th & thermal \\
\hline bs & backsheet & $\mathrm{bc}$ & back cover \\
\hline $\mathrm{pv}$ & PV module & $\mathrm{bp}$ & back plate \\
\hline ins & insulation & sky & sky \\
\hline \multicolumn{4}{|l|}{ Abbreviations } \\
\hline PW70 & Phase change material & NanoPCM & Nano-enhanced PCM \\
\hline PV & Photovoltaics & PW70 & Paraffin wax \\
\hline PCM/Graphene-silver & Paraffin wax/Graphene-silver & & \\
\hline
\end{tabular}




\section{Introduction}

Recently, phase change materials (PCMs) received a lot of attention for thermal storage applications due to the PCMs capability for energy storage. Thermal energy can be stored using latent heat, sensible heat and chemical energy approaches. Latent heat thermal energy storage has advantages of high energy density with small storage volume and allows for energy storage at a nearly constant (phase change) temperature during melting and solidification [1]. PCMs as latent heat storage mediums are widely used in solar energy applications [2], waste heat recovering in industries [3], and cooling of electronic devices [4]. Paraffin wax is the most common PCM that is used in many thermal storage applications due to the high latent heat storage, no phase segregation, chemically inert and availability at low cost [5]. Although paraffin wax has high latent heat storage, it exhibits low thermal conductivity $[6,7]$. Many efforts have been made to enhance the paraffin wax's thermal conductivity $[8,9]$. Carbon-based materials present high thermal conductivity and chemical inertness which attract the attention of researchers to improve the thermal conductivity of paraffin wax. The carbon-based materials carry the heat throughout the PCMs due to the open cell structure which connected with high thermal conductivity of graphitic ligaments [10-12]. Zhao et al. [13] investigated thermo-physical properties of a developed composite PCM composed of polyethylene glycol and biological porous carbon. Authors proved the highest thermal conductivity of $4.5 \mathrm{~W} \mathrm{~m}^{-1} \mathrm{~K}^{-1}$, which is about 10 times higher than the pristine PCM. In another research work, a novel carbonized wood/polyethylene glycol composite PCM was developed via a carbonization and vacuum impregnation process [14]. The authors achieved a prominent thermal conductivity value of $0.51 \mathrm{~W} \mathrm{~m}^{-1} \mathrm{~K}^{-1}$, which was approximately three times higher than the pristine PCM. Previous researches reported that the thermal performance of the PCM increased when nanoparticles infused with PCM [15-18]. The influence of nanomaterials in terms of phase-change characteristic, thermal conductivity and latent heat fusion of PCM have been investigated and experimentally validated by many researchers [19-21]. In a nutshell, based on the previous research work, 55-60\% of the thermal conductivity of organic PCMs improved with the addition of nanomaterials compared to their original form [22]. Min et al. [23] developed a novel shape-stabilized composite PCM composed of polyethylene glycol and radial mesoporous silica with efficient thermo-physical properties which makes this novel composite PCM as a promising candidate for building thermal energy storage applications. Past researches also stated 
that when the proportions of nanoparticles increase, the solidification and melting rates of PCMs are influenced due to the presence of nanoparticles [24].

When comparing the thermal conductivity of nanoparticles, graphene particles have better thermal conductivity and also better other thermal properties [25]. Better thermo-physical properties of graphene made it as a favorable candidate used as infusion and enhancement nanomaterial. Graphene is a two-dimensional sheet of $\mathrm{sp}^{2}$-hybridized carbon which is relatively easy to synthesize and cost effective [26]. Due to the different synthesis methods, there are variation of properties of graphene that has been reported [25]. For example, multi-layer graphene synthesized by exfoliation of graphene oxide layer, chemical vapor deposition (CVD) and micromechanical cleavage has different thermo-physical properties [27-29].

Other than graphene, silver (Ag) is also used as an infusion material because of good conductivity and chemical stability [30,31, 12]. Silver nanoparticles have been synthesized by gamma ray radiation, micro emulsion, photochemical reduction and electro chemical methods [32]. The exceptional characteristics of silver nanoparticles have made them applicable in various fields such as biomedical, drug delivery, water treatment, and agricultural industry [33, 34]. From the previous studies, PCM composites infused with single nanoparticles were widely studied and it is understood that the single nanoparticles enhanced the thermal properties of the PCMs. On the other hand, studies on hybrid nanoparticles or more than single nanoparticles infused with PCMs are very less and limited $[35,36]$. Thus, this has been an inspiration to researchers for developing the novel composite PCMs containing hybrid nanoparticles. Tafrishi et al. [37] conducted a molecular dynamic study to investigate the effect of adding hybrid nanoparticles including graphene and boron nitride nanosheets on the thermal properties of a developed PCM composite. The authors concluded that the developed PCM composite had more heat capacity, more thermal conductivity and a lower diffusion coefficient in comparison with pure PCM. In another research work, the effect of hybrid nanoparticles on the melting process of PCMs has been analyzed numerically [38]. The authors proved that the hybrid nanoparticles composed of $\mathrm{Ag}-\mathrm{MgO}$ demonstrate slight enhancements in the acceleration of the melting process.

In this research work, the paraffin-based hybrid nanomaterial (Graphene-Silver) has been studied to verify the thermo-physical properties enhancement of hybrid nanomaterial on paraffin wax (PCM). Thermo-physical properties and application in CPV/T systems of the hybrid PCM/Graphene-Silver nanocomposite is the first study to the best of authors' knowledge. Fourier- 
transform infrared (FTIR) test is conducted to study the chemical compatibility of hybrid PCM/Graphene-Silver nanocomposite. Differential scanning calorimetry (DSC) analyses are studied to analyze the melting point, enthalpy and specific heat capacity $\left(c_{\mathrm{p}}\right)$ of hybrid PCM/Graphene-silver nanocomposite. Thermal gravimetric analysis (TGA) and thermal conductivity tests are conducted to determine the thermal properties of hybrid PCM/GrapheneSilver nanocomposite. Electrical and thermal energy efficiencies of the hybrid PCM/GrapheneSilver nanocomposite in the solar thermal collector systems as coolant is investigated as well.

\section{Materials and methods}

\subsection{Materials}

Organic phase change material (PLUSICE A70) with melting point of $70{ }^{\circ} \mathrm{C}$, density of $890 \mathrm{~kg}$ $\mathrm{m}^{-3}$, volumetric heat capacity of $154 \mathrm{MJ} \mathrm{m}^{-3}$ and specific heat capacity of $2.2 \mathrm{~kJ} \mathrm{~kg}^{-1} \mathrm{~K}^{-1}$ is procured from Phase Change Materials Products Ltd Company [39]. PLUSICE A70 is also known as Paraffin Wax, PW70. Hybrid Graphene-Silver nanomaterial with particle size of $100 \mathrm{~nm}$ and ratio of 5:5, was purchased from US research nanomaterials, Inc. This nanocomposite (GrapheneSilver) is synthesized by sonochemical green synthesis method with the presence of oxygen functional groups. In the hybrid Graphene-Silver, graphene and silver has purity of 99 and 99.99\%, respectively [40]. Table 1, Represents the properties of the hybrid nanocomposite (GrapheneSilver).

Table 1 Properties of the hybrid nanocomposite (Graphene-Silver)

\begin{tabular}{lcc}
\hline Parameter & Graphene & Silver \\
\hline Purity & $99 \%$ & $99.99 \%$ \\
Thickness & $<5 \mathrm{~nm}$ & - \\
Diameter & $1 \mu \mathrm{m}-12 \mu \mathrm{m}$ & - \\
Specific surface area & $500-1200 \mathrm{~m}^{2} \mathrm{~g}^{-1}$ & $\sim 18-22 \mathrm{~m}^{2} \mathrm{~g}^{-1}$ \\
Density & - & $10.5 \mathrm{~g} \mathrm{~cm}^{-3}$ \\
Average particle size & - & $20 \mathrm{~nm}^{-1}$ \\
Nanoparticle morphology & $2 \mathrm{D}$ & Spherical \\
\hline
\end{tabular}




\subsection{Preparation of hybrid PCM/Graphene-Silver as a new class of nanocomposites}

Three different concentrations of hybrid Graphene-Silver (0.1, 0.2 and 0.3 mass\%) were loaded into the PCM (PW70). Mass values of PW70 with $59.940 \mathrm{~g}$ and hybrid Graphene-Silver powder with $0.06 \mathrm{~g}$ are measured separately using a microbalance (Explorer series, Ohaus) with measuring uncertainty of \pm 0.0001 . These amounts are used to prepare the hybrid PCM/Graphene-Silver nanocomposite with a 0.1 mass $\%$ of Graphene-Silver nanomaterial. The proposed amount of paraffin wax $(59.940 \mathrm{~g})$ is heated in a beaker ( $150 \mathrm{ml}$ volume) using a hot plate (RCT BASIC, IKA). The temperature of hot plate is adjusted to $100{ }^{\circ} \mathrm{C}$. PW70 is left for 15 minutes on the hot plate for melting and homogenization purpose. Afterwards, $0.06 \mathrm{~g}$ of hybrid Graphene-Silver powder is added to the beaker and stirred by a magnetic stirrer at $500 \mathrm{rpm}$. During the mixing process, the beaker is covered with an aluminum foil to prevent the formation of air bubbles during magnetic stirring process. Stirring process is conducted for $2 \mathrm{~h}$ continuously. The resultant hybrid $\mathrm{PCM} /$ Graphene-Silver nanocomposite is poured into a vial (14 $\mathrm{ml} \mathrm{NEST})$ to mold at room temperature. Same protocols are repeated to prepare nanocomposites with concentrations of 0.2 and 0.3 mass\% hybrid Graphene-Silver powder by adding 0.12 and $0.18 \mathrm{~g}$ of hybrid GrapheneSilver powder as filler to the melted PW70 of $59.880 \mathrm{~g}$ and $59.820 \mathrm{~g}$, respectively.

\subsection{Characterization of hybrid PCM/Graphene-Silver nanocomposites}

2.3.1. HRTEM and elemental analysis of hybrid Graphene-Silver nanoparticles

Morphology of the hybrid Graphene-Silver is investigated using HRTEM (JEOL JEM-ARM 200F) imaging at an accelerating voltage of $200 \mathrm{kV}$. About $1 \mathrm{mg}$ of hybrid Graphene-Silver is added onto the carbon-coated cupper grid. Energy dispersive X-ray spectroscopy (EDX, OXFORD INSTRUMENT) is used to confirm the elemental map imaging and observation of spatial distribution of all elements. The spot analysis is carried out to detect the quantitative distribution of elements in different portions of hybrid Graphene-Silver.

\subsubsection{Fourier transform infrared spectrum (FT-IR)}

The Fourier Transform Infrared spectrum (FTIR) of the hybrid PCM/Graphene-Silver nanocomposites is determined using a Perkin Elmer Spectrum Two-UATR. Spectra is detected using the integrated detector of MIR TGS $\left(15000-370 \mathrm{~cm}^{-1}\right)$. Scanning speed was $0.2 \mathrm{~cm} \mathrm{~s}^{-1}$ within the optimum scan range of $7800-450 \mathrm{~cm}^{-1}$. 


\subsection{Thermal properties measurement}

\subsubsection{Thermal conductivity measurement}

Thermal conductivity of the pure PW70 and hybrid PCM/Graphene-Silver nanocomposite samples are measured using a KD2 Pro thermal properties analyzer (Decagon, USA, version 5). This probe works with the principle of a transient hot wire technique. The TR-1 sensor (100 mm length, $2.4 \mathrm{~mm}$ diameter) is used for the thermal conductivity measurement. A programmable digital water bath (Wisd, 11Lit, WB-11) with temperature accuracy of $\pm 0.1^{\circ} \mathrm{C}$ and heating power of $1 \mathrm{~kW}$ is used for controlling the temperature within $\pm 1{ }^{\circ} \mathrm{C}$. Thermal conductivity of the nanocomposites (PCM/Graphene-Silver) is investigated at average temperature of $\sim 25^{\circ} \mathrm{C}$. The 14 $\mathrm{ml}$ vial consisting of the nanocomposite and sensor is placed inside a double wall beaker $(1000 \mathrm{ml}$ volume) covered with styrofoam to prevent the exchange of heat between sample and atmosphere. Those are wrapped using an aluminum foil to prevent the formation of air bubbles during the measurements. The deviation of the measured temperature is considered around $\pm 0.5{ }^{\circ} \mathrm{C}$. Each measurement is repeated three times to get the precise results. Since the temperature uniformity is highly important for the KD2 Pro, sample and sensor are allowed to achieve the temperature equilibrium for 30 minutes before any measurement. Reading time of the measurements is raised to 10 minutes for each measurement to ensure the accuracy of thermal conductivity results as well as reducing the error points indicated by decagon instrument.

2.4.2. Specific heat capacity $\left(c_{\mathrm{p}}\right)$, enthalpy and melting/solidification temperature measurements

In this study, the specific heat capacity $\left(c_{\mathrm{p}}\right)$, enthalpy and melting/solidification temperature measurements of the pure PCM and hybrid PCM/Graphene-Silver nanocomposite samples are performed using a differential scanning calorimetry (DSC). DSC-1000/C (Linseis, Germany) is a high resolution $(0.03 \mu \mathrm{W})$ instrument and the measurements are conducted using aluminum crucibles of $40 \mu \mathrm{l}$. The temperature range for measurements is between $25-250{ }^{\circ} \mathrm{C}$ with the heating rate of $10{ }^{\circ} \mathrm{C} \mathrm{min}^{-1}$. The nanocomposite samples are tightly sealed in a regular aluminum crucible with the capacity of $40 \mu \mathrm{l}$ under a nitrogen atmosphere with a flow rate of $20 \mathrm{ml} \mathrm{min}{ }^{-1}$. The temperature repeatability and calorimetric precision are $\pm 0.1{ }^{\circ} \mathrm{C}$ and $\pm 1 \%$, respectively. Temperature and enthalpy calibrations for this DSC are carried out employing four standard reference samples (Indium, Tin, Lead and Zinc) provided by the supplier. The experimentally 
achieved data for specific heat capacity, enthalpy and melting/solidification temperature values of the pure paraffin wax is in agreement with the values provided by supplier [39]. One uniform protocol for $c_{\mathrm{p}}$, enthalpy and melting/solidification temperature measurements of the hybrid PCM/Graphene-Silver nanocomposites are adjusted in order to ensure the accuracy of results. All DSC measurements are performed using the heating rate of $10{ }^{\circ} \mathrm{C} \mathrm{min}^{-1}$ under nitrogen atmosphere.

\subsubsection{Thermal stability test}

Thermal gravimetric analysis (TGA) of the hybrid PCM/Graphene-Silver nanocomposites are conducted using Perkin Elmer TGA 4000. A $180 \mu$ l alumina crucible (with temp. $\sim 1750{ }^{\circ} \mathrm{C}$ ) under an ultra-high pure nitrogen gas flow of $19.8 \mathrm{ml} \mathrm{min}^{-1}$ with the gas pressure of 2.6 bar is selected to examine the samples. The utilized heating rate is $10{ }^{\circ} \mathrm{C} \mathrm{min}-1$ for raising the temperature from 30 to $800{ }^{\circ} \mathrm{C}$. About $15 \mathrm{mg}$ of hybrid PCM/Graphene-Silver nanocomposite sample is used for the decomposition temperature measurement. The obtained data is analyzed using Pyris Software.

\subsubsection{Accelerated thermal cycle test}

Thermal reliability of the developed PCM/Graphene-Silver nanocomposites and pure PCM was determined using a custom designed accelerated thermal cycler. The utilized thermal cycler has three chambers built to run three samples that each chamber can be controlled individually. Each chamber is equipped with two thermocouples, a sample holder, heater and cooler. The thermocouple can be moved vertically up and down which is controlled through a stepper motor. After reaching the maximum temperature, the heating unit is switched off, while the cooling unit is switched on. A digital controller is provided to set the maximum operation temperature and temperature differences. The minimum operation temperature of the employed Peltier cooling system is $25^{\circ} \mathrm{C}$. Computer collects the acquired experimental data through PicoLog Hardware. The thermocouple output is converted to appropriate temperature values by using PicoLog software. The developed nanocomposites and pure PCM were placed in a cupper crucible. The DSC data is collected at 0,100 and 200 cycles to determine the thermal cycling performance of the developed nanocomposites and pure PCM. This accelerated thermal cycler equipment is designed and implemented at RCNMET, Sunway University, Malaysia. 


\subsection{Performance investigation of Concentrated Photovoltaic Thermal (CPV/T) Collector}

After evaluation of the thermal properties of the hybrid PCM/Graphene-silver nanocomposite samples, it is important to assess their effect on the performance of a suitable solar system. The hybrid Concentrated Photovoltaic/Thermal (CPV/T) solar system was selected due to its suitability to the high melting temperature of the applied paraffin wax $\left(\sim 70{ }^{\circ} \mathrm{C}\right)$. The assessment was applied on the nanocomposite samples at different nanoparticles concentrations of $0.1,0.2$ and 0.3 mass $\%$. The CPV/T system consists of a PV panel with solar concentrators on both sides as shown in Fig. 1. A cooling fluid channel exists below the PV panel and the nanocomposite layer exists in between the panel and the cooling channel to provide the thermal regulation for the PV panel. The system is insulated from all the side walls, except inlet and outlet of cooling fluid to avoid any heat leakage. This allows the heat to be collected only by the cooling fluid, which is considered as one of the main targets of using hybrid PV/T and CPV/T systems. The system is exposed, as well, to atmospheric temperature from the upper and bottom sides. However, an insulation layer has been added below the cooling channel to minimize the heat losses to the atmosphere. The assessment of the performance has covered the average PV panel temperature, the temperature gain across the cooling fluid and the thermal and electrical efficiencies of the system. The results are compared to the same performance parameters using the pure paraffin wax. The required governing energy equations are developed and solved numerically using Matlab 2017b program. A schematic diagram for the studied hybrid system is shown in Fig. 1. 


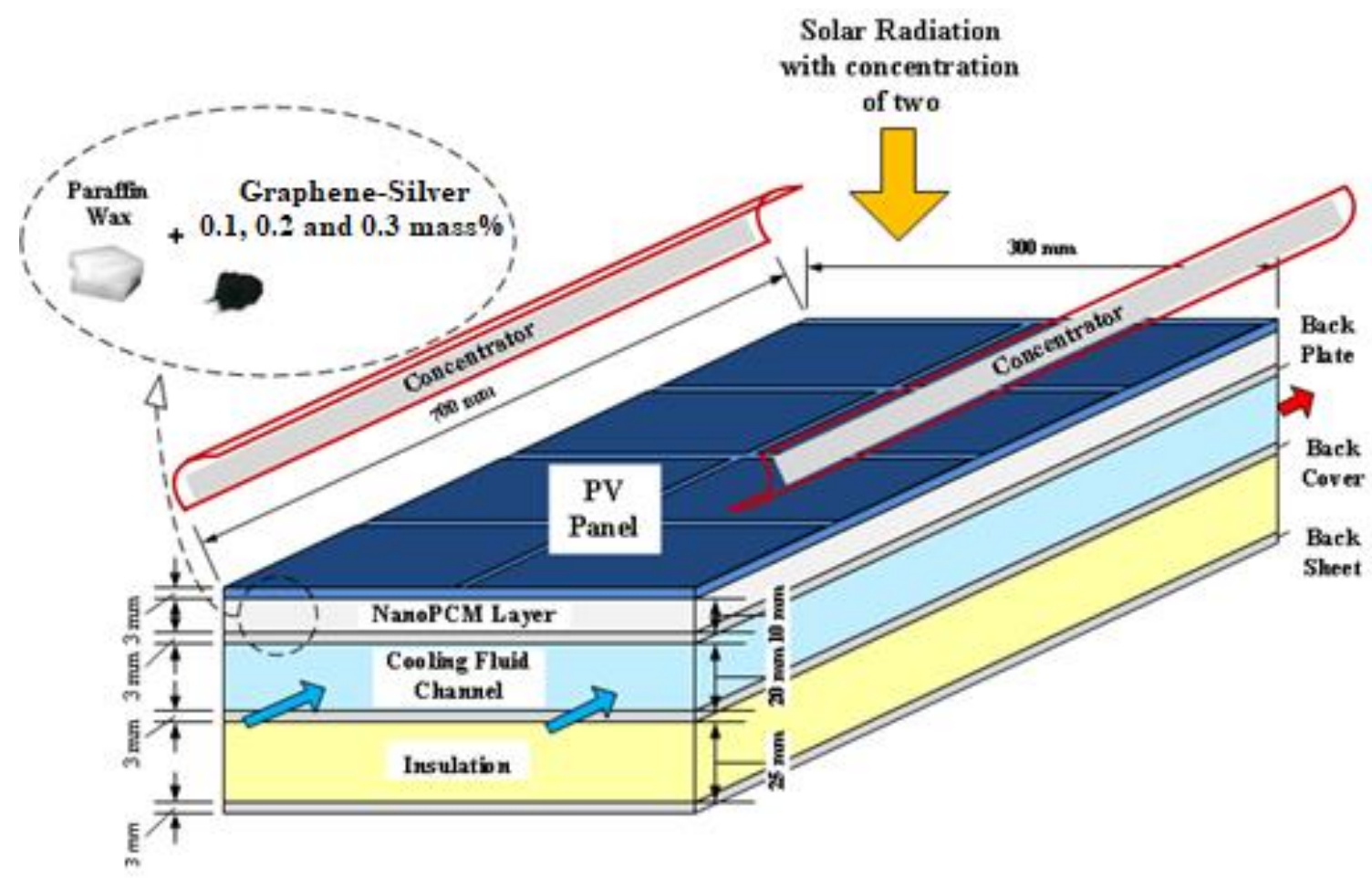

Fig. 1 Schematic diagram for the studied hybrid CPV/T system with hybrid PCM/Graphene-Silver nanocomposite layer

\subsubsection{Mathematical model}

In this section, the governing energy equations of the CPV/T system is explained. The energy equations are derived from an energy balance along each layer from the system and an evaluation of the parameters that affect the rate of change of the internal energy of each layer due to the heat exchange with the neighboring layers. The energy equations are summarized in Table 2. As simulating the heat transfer through the nanocomposite layer is relatively complicated, it has been divided into the sub-layer attached to the PV panel, the sub-layer attached to the back cover and the sub-layer in between them. The energy equations throughout these three sub-layers are mentioned in Table 3, while the constant parameters implemented in the study are presented in Table 4. 
Table 2 Governing equations of the hybrid PV/T system with opticle filtration

\begin{tabular}{|c|c|c|}
\hline Equation for & Governing Equations & Eq. \\
\hline PV panel & 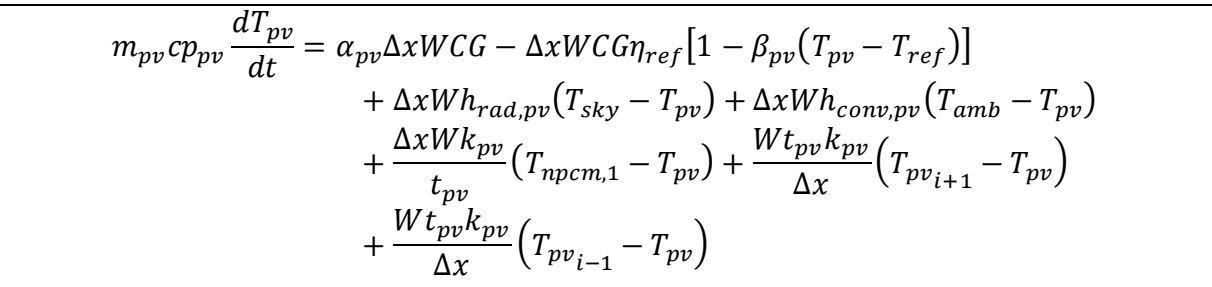 & Eq. 1 \\
\hline Back cover & $\begin{aligned} m_{b c} c p_{b c} \frac{d T_{b c}}{d t}=\frac{\Delta x W k_{b c}}{t_{b c}}\left(T_{n p c m, n}-T_{b c}\right)+\Delta x W h_{c o n v, c f}\left(T_{c f}-T_{b c}\right) \\
+\frac{W t_{b c} k_{b c}}{\Delta x}\left(T_{b c_{i+1}}-T_{b c}\right)+\frac{W t_{b c} k_{b c}}{\Delta x}\left(T_{b c_{i-1}}-T_{b c}\right)\end{aligned}$ & Eq. 2 \\
\hline Cooling fluid & $m_{c f} c p_{c f}\left(T_{\mathrm{cf}, \text { out }}-T_{\mathrm{cf,in}}\right)=\Delta x W h_{c o n v, c f}\left(\mathrm{~T}_{\mathrm{bc}}-\mathrm{T}_{\mathrm{cf}}\right)+\Delta x W h_{c o n v, c f}\left(\mathrm{~T}_{\mathrm{bp}}-\mathrm{T}_{\mathrm{cf}}\right)$ & Eq. 3 \\
\hline Back plate & $\begin{array}{c}m_{b p} c p_{b p} \frac{d T_{b p}}{d t}=\Delta x W h_{c o n v, c f}\left(\mathrm{~T}_{\mathrm{cf}}-\mathrm{T}_{\mathrm{bp}}\right)+\frac{1}{R_{b s}}\left(T_{b s}-T_{\mathrm{bp}}\right)+\frac{W t_{b p} k_{b p}}{\Delta x}\left(T_{\mathrm{bp}}-T_{\mathrm{bp}}\right) \\
+\frac{W t_{b p} k_{b p}}{\Delta x}\left(T_{\mathrm{bp}}-T_{\mathrm{bp}}\right)\end{array}$ & Eq. 4 \\
\hline Back sheet & $\begin{array}{c}m_{b s} c p_{b s} \frac{d T_{b s}}{d t}=\frac{1}{R_{b s}}\left(T_{b p}-T_{\mathrm{bs}}\right)+\Delta x W h_{r a d, b s}\left(T_{\text {ground }}-T_{\mathrm{bs}}\right)+\Delta x W h_{c o n v, b s}\left(T_{a m b}-T_{\mathrm{bs}}\right) \\
+\frac{W t_{b s} k_{b s}}{\Delta x}\left(T_{\mathrm{bs}_{i+1}}-T_{\mathrm{bs}}\right)+\frac{W t_{b s} k_{b s}}{\Delta x}\left(T_{\mathrm{bs}_{i-1}}-T_{\mathrm{bs}}\right)\end{array}$ & Eq. 5 \\
\hline
\end{tabular}

${ }^{*} T_{i+1}$ and $T_{\mathrm{i}-1}$ are the temperatures of the layer to the right and left directions on the $\mathrm{x}$-axis from the calculation point

Table 3 Governing equations through the hybrid PCM/Graphene-Silver nanocomposite layer

\begin{tabular}{|c|c|c|}
\hline Equation for & Governing Equations & Eq. \\
\hline First layer & $\begin{aligned} m_{n p c m} c p_{n p c m} \frac{d T_{n p c m, 1}}{d t} & \\
= & \frac{\Delta x W k_{p v}}{t_{p v}}\left(T_{p v}-T_{n p c m, 1}\right)+\frac{\Delta x W k_{n p c m}}{\Delta y}\left(T_{n p c m, 2}-T_{n p c m, 1}\right) \\
& +\frac{W \Delta y k_{n p c m}}{\Delta x}\left(T_{n p c m, 1_{i+1}}-T_{n p c m, 1}\right) \\
& +\frac{W \Delta y k_{n p c m}}{\Delta x}\left(T_{n p c m, 1_{i-1}}-T_{n p c m, 1}\right)\end{aligned}$ & Eq. 6 \\
\hline Last layer & $\begin{aligned} m_{n p c m} c p_{n p c m} \frac{d T_{n p c m, n}}{d t} & \\
& =\frac{\Delta x W k_{b c}}{t_{b c}}\left(T_{b c}-T_{n p c m, n}\right)+\frac{\Delta x W k_{n a n o p c m}}{\Delta y}\left(T_{n p c m, n-1}-T_{n p c m, n}\right) \\
& +\frac{W \Delta y k_{n p c m}}{\Delta x}\left(T_{n p c m, n_{i+1}}-T_{n p c m, n}\right) \\
& +\frac{W \Delta y k_{n p c m}}{\Delta x}\left(T_{n p c m, n_{i-1}}-T_{n p c m, n}\right)\end{aligned}$ & Eq. 7 \\
\hline
\end{tabular}




\begin{tabular}{|c|r|r|}
\hline & $m_{n p c m} c p_{n p c m} \frac{d T_{n p c m, j}}{d t}$ & \\
Layers in & $=\frac{\Delta x W k_{n p c m}}{\Delta y}\left\{\left(T_{n p c m, j+1}-T_{n p c m, j}\right)+\left(T_{n p c m, j-1}-T_{n p c m, j}\right)\right\}$ & Eq. 8 \\
between & $+\frac{W \Delta y k_{n p c m}}{\Delta x}\left\{\left(T_{n p c m, j} j_{i+1}-T_{n p c m, j}\right)+\left(T_{n p c m, j} j_{i-1}-T_{n p c m, j}\right)\right\}$ & \\
& & \\
\hline
\end{tabular}

Using the numerical results, the electrical and thermal energy outputs of the CPV/T system were evaluated as follows:

$$
\begin{gathered}
E_{e l, \text { out }}=\int_{0}^{\text {time of the study }} L W C G \eta_{r e f}\left[1-\beta_{p v}\left(T_{p v}-T_{r e f}\right)\right] \\
E_{t h}=\int_{0}^{\text {time of the study }} m_{c f} c p_{c f}\left(T_{\mathrm{cf}, \mathrm{out}}-T_{\mathrm{cf}, \mathrm{in}}\right)
\end{gathered}
$$

Consequently, the electrical and thermal efficiencies were calculated using the equations described in Eq. 11 and Eq. 12:

$$
\begin{gathered}
\eta_{e l}=\frac{E_{e l, o u t}}{E_{i n}} \\
\eta_{t h}=\frac{E_{t h}}{E_{\text {in }}}
\end{gathered}
$$

where, $E_{\text {in }}$ is the input energy, which is evaluated as:

\begin{tabular}{|c|c|c|c|}
\hline Parameter & Value & Parameter & Value \\
\hline$L$ & $0.7 \mathrm{~m}$ & $\Delta x$ & $0.05 \mathrm{~m}$ \\
\hline$W$ & $0.3 \mathrm{~m}$ & $\Delta y$ & $0.002 \mathrm{~m}$ \\
\hline $\boldsymbol{t}_{p v}, \boldsymbol{t}_{b c}, \boldsymbol{t}_{b p}$ and $\boldsymbol{t}_{b s}$ & $3 \mathrm{~mm}$ & $\alpha_{p v}$ & 0.945 \\
\hline$t_{i n s}$ & $25 \mathrm{~mm}$ & $\varepsilon_{p v}$ & 0.9 \\
\hline$t_{c f}$ & $20 \mathrm{~mm}$ & $\beta_{p v}$ & $0.005^{\circ} \mathrm{C}^{-1}$ \\
\hline$t_{\text {npcm }}$ & $10 \mathrm{~mm}$ & $\varepsilon_{b s}$ & 0.09 \\
\hline$T_{r e f}$ & $25^{\circ} \mathrm{C}$ & $u_{a}$ & $0 \mathrm{~m} \mathrm{~s}^{-1}$ \\
\hline$C$ & 2 & $m_{c f}$ & $0.002 \mathrm{~kg} \mathrm{~s}^{-1}$ \\
\hline time of the study & 3 hours $=10800 \mathrm{sec}$ & $\eta_{\text {ref }}$ & $20 \%$ \\
\hline$\Delta t$ & $10 \mathrm{sec}$ & & \\
\hline
\end{tabular}

$$
E_{\text {in }}=\int_{0}^{\text {time of the study }} L W C G
$$

Table 4 Constant parameters used in the study 


\subsubsection{Input parameters}

Thermo-physical parameters of the pure PCM and hybrid PCM/Graphene-Silver nanocomposites are used from the acquired experimental results. The thermal properties including, thermal conductivity, specific heat capacity, latent heat of fusion and melting temperature of the samples have been obtained from the sections of 3.3, 3.4 and 3.5. The values of the thermal conductivity of the samples, in the liquid phase, are assumed as equal to the solid phase values. On the other side, and due to the limitation of the data, the density of all the samples was assumed as constant value equals to $800 \mathrm{~kg} \mathrm{~m}^{-3}$.

\section{Results and Discussion}

\subsection{Morphological characterization of hybrid Graphene-Silver nanomaterial}
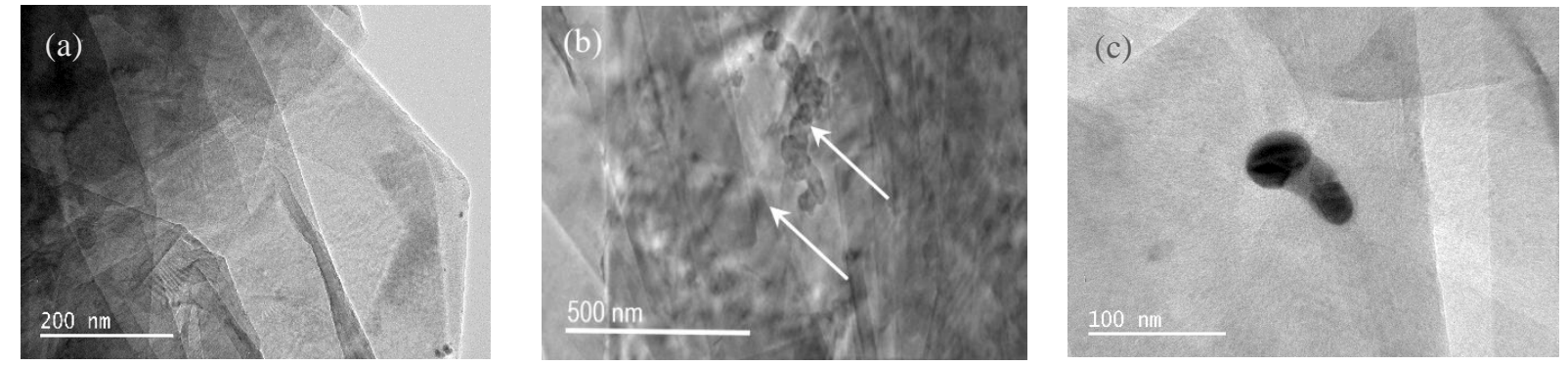

Fig. 2 HRTEM micrographs of hybrid Graphene-Silver showing the morphology: (a) edges of the few layered graphene flakes, (b) Silver nanoparticles in the graphene sheets, (c) Orientation of the vicinity Silver nanoparticles in the crystalline graphene sheets

Fig. 2, presents the HRTEM micrographs of hybrid Graphene-Silver showing the morphology of graphene sheets and silver nanoparticles. Fig. 2(a), showed the HRTEM image, presenting a few layers of thin and transparent graphene nanosheets. It also indicates that the layers are stacked together by overlapping each other with a folded manner [41]. Fig. 2(b), shows the HRTEM image of silver nanoparticles filled graphene sheets. HRTEM analysis exposed that graphene sheets are uniformly intercalated with the silver nanoparticles. The silver nanoparticles in the graphene layers display a dark and uniform contrast with the surrounding of transparent graphene flakes. Besides, it is also understood that the intercalated silver nanoparticles in graphene flakes can orient by linking each other [42] which can help to connect the graphene flakes and increase the conductive path in the base materials [43,44]. Fig. 2(c), exhibits that the existing orientation of vicinity silver nanoparticles in the graphene sheets and the used graphene flakes are crystalline $[41,25]$. 


\subsection{Chemical structure characterization (FTIR) results}

Fig. 3, shows the FTIR spectrum of paraffin wax and different concentration of hybrid Graphene-Silver nanomaterial infused paraffin wax (PCM/Graphene-Silver) in the frequency range of 4000-450 $\mathrm{cm}^{-1}$. The FTIR spectrum of paraffin wax and hybrid Graphene-Silver infused paraffin wax shows almost identical peak and there is no new peak observed. The similar peaks show that there is only physical interaction between paraffin wax and hybrid Graphene-Silver nanomaterial $[45,46]$. The chemical structures of the pure organic paraffin wax and the hybrid PCM/Graphene-Silver nanocomposites are analysed using FTIR spectroscopy. The FTIR spectrum result is shown in Fig. 3. The FTIR spectrum for hybrid PCM/Graphene-Silver nanocomposites and pure PW70 are shown separately. Shifts in the characteristic peaks reveals the presence of $\mathrm{C}-\mathrm{H}_{2}$ and $\mathrm{C}-\mathrm{H}_{3}$ groups in the samples. The major absorption peaks for the PW70 and different concentration mixture of hybrid Graphene-Silver nanomaterial occurs at $2916 \mathrm{~cm}^{-1}$, $2848 \mathrm{~cm}^{-1}, 1464 \mathrm{~cm}^{-1}$, and $721 \mathrm{~cm}^{-1}$. The peaks at $2916 \mathrm{~cm}^{-1}$ and $2848 \mathrm{~cm}^{-1}$ show the $\mathrm{C}-\mathrm{H}_{2}$ bonding of the paraffin wax [47]. The peak defines that the stable balance of attractive and repulsive forces between carbon and hydrogen atoms exists in paraffin wax [48]. The presence of oxygen functionalities in the samples is detected in peaks at $1464 \mathrm{~cm}^{-1}$ and $721 \mathrm{~cm}^{-1}$ due to $\mathrm{C}^{-} \mathrm{H}_{3}$ stretching vibrations [49]. Clearly, it is seen that the wavenumbers $\left(\mathrm{cm}^{-1}\right)$ of characteristic peaks of all composite samples with varying hybrid Graphene/Silver nanomaterial loading mass fraction is similar. The similarity in peak for different concentration of hybrid Graphene-Silver nanomaterial is due to the dominance of paraffin wax chemical structure [50]. From the observation of the entire peak, it can be concluded that there are no peaks in the spectrum of nanoparticles corresponding to its component, paraffin wax. From the FTIR results, it has been proven that there is no chemical interaction that changes the nature of paraffin wax functional group [51]. 


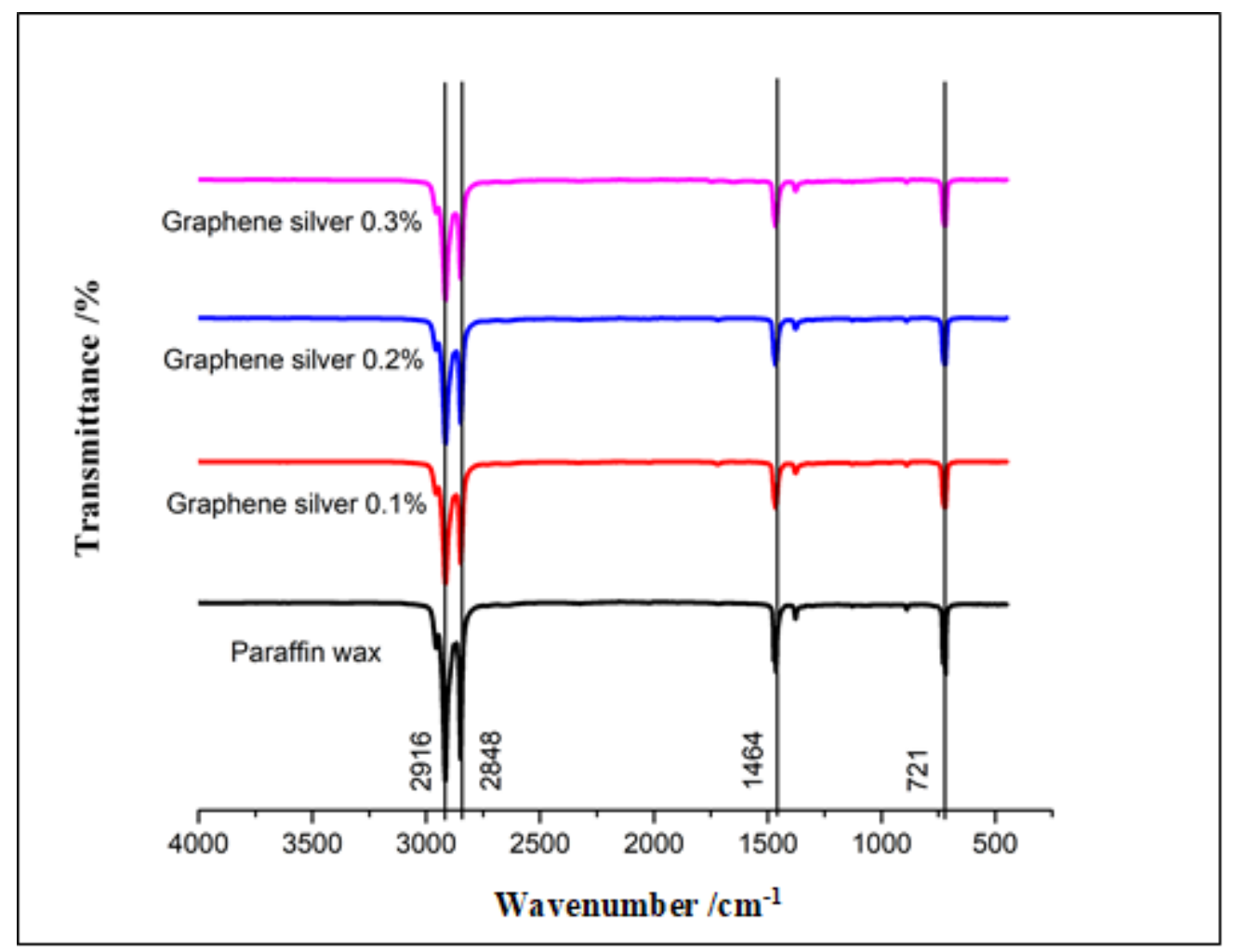

Fig. 3 FTIR spectrum of paraffin wax and different concentration mixture of hybrid Graphene-Silver nanomaterial

\subsection{Thermal conductivity of organic PCM dotted with hybrid Graphene-Silver nanomaterial}

Thermal conductivity is an important parameter for a PCM that influence the rate of thermal energy charging and/or discharging throughout the day and night. Fig. 4, illustrates the experimentally obtained thermal conductivity data of hybrid PCM/Graphene-Silver nanocomposite with varying loadings of silver induced Graphene (Gr-Ag) flakes. Y-axis error bars with the measured thermal conductivity are the average error points with the consecutively repeated measured values. The average error point of the three consecutively readings is found to be \pm 0.003 . This low value of error points evidences the measurement accuracy of the thermal conductivity of the hybrid PCM/Graphene-Silver nanocomposite samples. It is found that the experimentally acquired thermal conductivity value of pure PCM is $\sim 0.2 \mathrm{~W} \mathrm{~m}^{-1} \mathrm{~K}^{-1}$ which matches with the previously reported value of $\sim 0.21 \mathrm{~W} \mathrm{~m}^{-1} \mathrm{~K}^{-1}$ [52]. It is seen that a thermal conductivity is increased with the increase of hybrid Graphene-Silver nanomaterial loading in the PCM. Thermal conductivity of the as prepared hybrid PCM/Graphene-Silver nanocomposites are found 
$\sim 0.212, \sim 0.214$ and $\sim 0.219 \mathrm{~W} \mathrm{~m}^{-1} \mathrm{~K}^{-1}$ for the loading of hybrid Graphene-Silver nanomaterial of $0.1,0.2$ and 0.3 mass $\%$, respectively. These enhancements of thermal conductivities are $\sim 8, \sim 9$ and $\sim 11 \%$ respectively over the matrix PCM. These results can be comparable with the work conducted by Wang, et al. [53], where paraffin wax (PW) based MWCNTs nanocomposites provided the thermal conductivity enhancement of $\sim 11,16$ and $35 \%$ for the mass $\%$ of $0.2,0.5$ and 2 of MWCNTs respectively in solid state of about $30^{\circ} \mathrm{C}$. The enhancement of thermal conductivity in the hybrid PCM/Graphene-Silver nanocomposites could be more likely because of very high thermal conductivity of graphene flakes [54] and it possesses ultra-thin surfaces areas with negligible thickness leading to $\sim$ zero aspect ratio of graphene flakes [55]. Graphene flakes with these attributes more possibly can create a percolation conducting network in the PCM matrix. At this stage, tunneling effects occur between adjacent graphene flakes, creating it very effective conductive materials [44]. As the graphene flakes create a complete conductive path by contacting the flakes in the percolation, afterwards further rise of graphene flakes rises the number of conducting networks (as shown in the inset of Fig. 4) until the conductivity levels off [44].

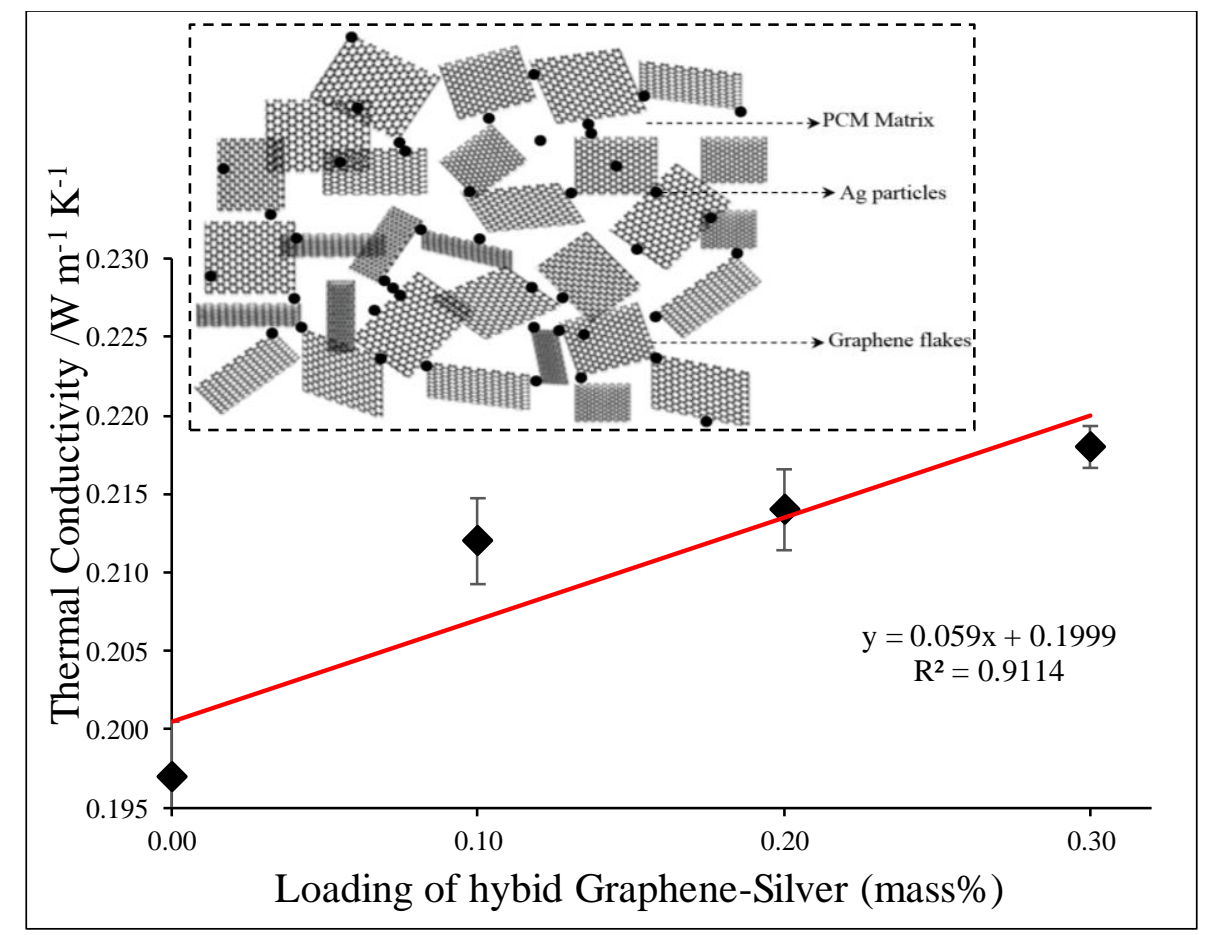

Fig. 4 Experimental data of the thermal conductivity measurements of hybrid PCM/Graphene-Silver nanocomposite as a function of hybrid Graphene-Silver nanomaterial loading. Inset is the schematic of the Graphene and silver nanoparticles percolations in the PCM matrix 
Graphene has strong ability to generate continuous thermally conductive chains due to their negligible aspect ratio which results in the high improvements of thermal conductivity characteristic [56]. On the other hand, spherical shape of silver nanoparticles prevail together with the graphene flakes by interfacing each other in PCM matrix [43] as shown in the inset of Fig. 4. Where silver nanoparticles help the electron through hopping from one graphene flake to other in the matrix and energy transport inside the matrix becomes stronger [57]. In spite of that, effect of interfacial thermal resistance among the hybrid Graphene-Silver nanomaterial and PCM matrix cannot be overrate in the solid-state hybrid PCM/Graphene-Silver nanocomposites. This interfacial thermal boundary resistance can be reason to hinder the enhancement of thermal conductivity of the hybrid PCM/Graphene-Silver nanocomposites as the nanoparticle dimensionality escalates based on the results for two-dimensional materials included graphene nanosheets [58].

\subsection{Specific heat capacity $\left(c_{\mathrm{p}}\right)$ of PCM and nano-PCM}

Specific heat capacity $\left(c_{\mathrm{p}}\right)$ is one of the prominent parameters for calculation, assessment and design of thermal systems [59]. Thermal energy storage performance of the pure organic paraffin wax and hybrid PCM/Graphene-Silver nanocomposites are examined by using DSC. Table 5, presents data for $c_{\mathrm{p}}$ measurements of pure organic PCM and hybrid PCM/Graphene-Silver nanocomposites.

Table 5 Experimentally acquired data for $c_{\mathrm{p}}$ measurements of pure paraffin wax and hybrid $\mathrm{PCM} / \mathrm{Graphene-Silver}$ (PCM/Gr-Ag) nanocomposites

\begin{tabular}{ccc}
\hline \multirow{2}{*}{ Samples } & \multicolumn{2}{c}{ Specific heat capacity $\left(\mathrm{J} \mathrm{g} \mathrm{g}^{-1} \mathrm{~K}^{-1}\right)$} \\
\cline { 2 - 3 } & \multicolumn{2}{c}{ Temperature $\left({ }^{\circ} \mathrm{C}\right)$} \\
\cline { 2 - 3 } & $\begin{array}{c}\text { Low temperature }(\sim 25 \\
\text { High temperature }(\sim 250\end{array}$ \\
\hline Pure paraffin wax & 2.1 & $\left.{ }^{\circ} \mathrm{C}\right)$ \\
Hybrid PCM/Gr-Ag(0.1 mass\%) & 1.9 & 3.11 \\
Hybrid PCM/Gr-Ag(0.2 mass\%) & 2.1 & 3.44 \\
Hybrid PCM/Gr-Ag(0.3 mass\% $)$ & 2.4 & 3.86 \\
\hline
\end{tabular}

Table 5, presents that $c_{\mathrm{p}}$ values for pure organic paraffin wax in the temperatures of $\sim 25$ and $\sim 250{ }^{\circ} \mathrm{C}$ were 2.1 and $3.10\left(\mathrm{~J} \mathrm{~g}^{-1} \mathrm{~K}^{-1}\right)$, respectively. Acquired experimentally data for $c_{\mathrm{p}}$ value of 
the pure paraffin wax at $25^{\circ} \mathrm{C}$ is in agreement with the provided data by supplier [39]. As it is clear from the achieved data, the $c_{\mathrm{p}}$ value increases for pure PCM at elevated temperatures. The mechanism for increasing specific heat capacity at elevated temperatures can be described due to vibrational, rotational and translation of molecules at higher temperatures. Heating up a substance will cause to increase the average energy of molecules which will lead to store more amount of energy [59]. Acquired experimentally data indicates that the changes of $c_{\mathrm{p}}$ value for hybrid PCM/Graphene-Silver nanocomposite $(0.1$ mass $\%)$ in low temperature $\left(\sim 25^{\circ} \mathrm{C}\right)$ is negligible $\left(c_{\mathrm{p}}=\right.$ $\left.1.9 \mathrm{~J} \mathrm{~g}^{-1} \mathrm{~K}^{-1}\right)$. The increment of $c_{\mathrm{p}}$ value at high temperature $\left(\sim 250{ }^{\circ} \mathrm{C}\right)$ is $\sim 11 \%$. The DSC results for hybrid PCM/Graphene-Silver nanocomposite (0.2 mass\%) indicates same result of $c_{\mathrm{p}}$ value $\left(c_{\mathrm{p}}=2.2 \mathrm{~J} \mathrm{~g}^{-1} \mathrm{~K}^{-1}\right)$ as pure PCM in low temperature $\left(\sim 25^{\circ} \mathrm{C}\right)$. However, enhancement of $\sim 29.5 \%$ is achieved in high temperature $\left(\sim 250^{\circ} \mathrm{C}\right)$ for the nanocomposite with 0.2 mass $\%$ loading of hybrid Graphene-Silver nanoparticles. $c_{\mathrm{p}}$ values of hybrid PCM/Graphene-Silver nanocomposite $(0.3$ mass\%) reveals $\sim 14 \%$ enhancement at low temperature $\left(\sim 25^{\circ} \mathrm{C}\right)$ and $\sim 40 \%$ increment at high temperature $\left(\sim 250^{\circ} \mathrm{C}\right)$. According to the literature, enhancement of $25 \%$ in specific heat capacity of nanocomposites can be achieved compared with the base substance due to the presence of nanoparticles [60, 61]. A theoretical model was applied by Wang et al. [53] to investigate the influence of particle size on the $c_{\mathrm{p}}$ value. They concluded that the enhancement of $c_{\mathrm{p}}$ value can be obtained by the reduction of nanoparticle size. Less number of bonds in the surface area of the lattice of the nanoparticles causes the atoms to be less constrained. Lower natural frequency and higher amplitude of the vibrations of the atoms in the surface area can allow the bonds to act like spring. This phenomenon can cause to creation of interface interaction of atoms in surface area of two-dimensional materials (because of high surface area) with high surface energy atoms of the organic pure paraffin ( $\mathrm{C}-\mathrm{H}$ bonds). The created interactions between atoms can be the reason of the enhanced specific heat capacity of hybrid PCM/Graphene-Silver nanocomposites. This mechanism is applicable in high temperatures as the temperature elevates the vibration of atoms. Enhancement of vibration will increase specific heat capacity which is proved experimentally in this study for new class of nanocomposites (hybrid PCM/Graphene-Silver) with different mass fraction loadings of hybrid Graphene-Silver nanomaterial. Due to the $\mathrm{C}-\mathrm{H}$ bond in the structure of organic PCMs and high surface area of two-dimensional inorganic compound (hybrid GrapheneSilver nanomaterial) it can be proposed that there is electrostatic interaction between the induced hybrid Graphene-Silver in PW70. The aforementioned interface interaction will cause to 
crystallize the particles of paraffin wax on the specific surface area of hybrid Graphene-Silver nanomaterial. Large specific surface area and specific surface energy will contribute to enhancement of the specific heat capacity. The promising thermodynamic efficiencies at higher operating temperatures can cause to reduce the final cost of the thermal systems which are working in the basis of thermal storage and thermal conductivity. An inexpensive method to decrease the cost of systems is to enhance the specific heat capacities of organic/inorganic PCMs by doping them with minute concentration of nanoparticles. According to the comprehensive study performed by Malik [62] reported that the cost of solar thermal power systems can be reduced by $15 \%$ when specific heat capacity is increased by $30 \%$. The above-mentioned model can be extended for organic PCMs as well. The required amount of thermal energy storage media in a concentrated solar power plant can significantly reduce with enhancement of specific heat capacity followed by a consequent reduction in the cost of electricity.

\subsection{Enthalpy and melting/solidification temperature of the hybrid PCM/Graphene-Silver nanocomposites}

Enthalpy and melting/solidification temperature characterizations of the hybrid PCM/Graphene-Silver nanocomposites and pure PCM are performed by using DSC. Fig. 5, illustrates the enthalpy results for pure PCM and hybrid nanocomposites with different mass fractions of hybrid Graphene-Silver nanomaterial. Table 6, represents the experimentally acquired data for Enthalpy and melting/solidification temperature of the developed nanocomposites. Melting and solidification temperatures of pure PW70 are $69.8^{\circ} \mathrm{C}$ and $50.4{ }^{\circ} \mathrm{C}$, respectively, which is in good agreement with the provided data by supplier of the pure PCM [39]. It is observed that with the addition of hybrid Graphene-Silver nanomaterial to pure paraffin wax, the melting point was increased slightly from 69.8 to $73.2{ }^{\circ} \mathrm{C}$ for the highest concentration $(0.3$ mass $\%)$ of hybrid Graphene-Silver nanomaterial, while the solidification temperature is found to be $53.4{ }^{\circ} \mathrm{C}$. The slight increment is observed because of the interface interaction between high surface energy atoms of pure paraffin wax and high surface area of hybrid Graphene-Silver nanomaterial. The increment of melting point confirms the explained mechanism of enhancement in specific heat capacity. Melting point of developed hybrid PCM/Graphene-Silver nanocomposite with loading concentration of 0.1 and 0.2 mass $\%$ is found to be 72.2 and $73.1{ }^{\circ} \mathrm{C}$, respectively. Solidification temperature of the developed nanocomposites is found to be 52.3 and $53.1{ }^{\circ} \mathrm{C}$ for the loading 
concentrations of 0.1 and 0.2 mass \%, respectively. It is observed from the DSC curves that the endothermic enthalpy value decreases with hybrid Graphene-Silver nanomaterial as additive. The measured latent heat of melting and latent heat of solidification for the pure paraffin wax are $\sim 110.7 \mathrm{~J} \mathrm{~g}^{-1}$ and $\sim 90.6 \mathrm{~J} \mathrm{~g}^{-1}$, respectively. DSC measurement for the latent heat of melting of the hybrid PCM/Graphene-Silver nanocomposites with the loading concentrations of $0.1,0.2$ and 0.3 mass\% represented values of $\sim 75.6, \sim 78.2$ and $\sim 88.8 \mathrm{~J} \mathrm{~g}^{-1}$, respectively. This indicates the release of energy in melting and heat transfer is enhanced in this crucial point. The experimentally acquired data for the latent heat of solidification for the developed hybrid PCM/Graphene-Silver nanocomposites represented values of $\sim 71.7, \sim 74.3$ and $\sim 84.2 \mathrm{~J} \mathrm{~g}^{-1}$ for the loading concentrations of $0.1,0.2$ and 0.3 mass $\%$, respectively.

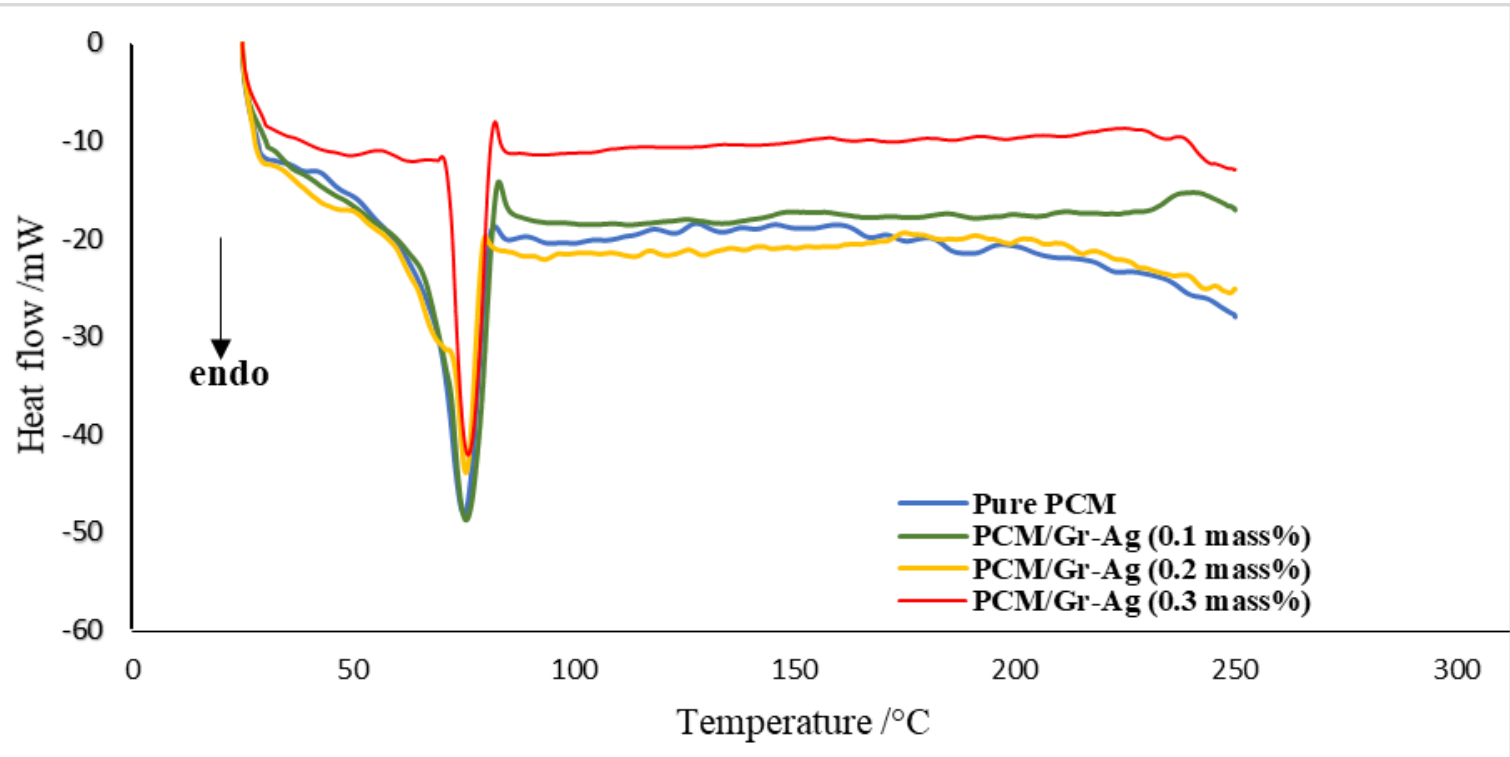

Fig. 5 DSC curve for Enthalpy and melting point of hybrid PCM/Graphene-Silver (PCM/Gr-Ag) nanocomposites and pure PCM 
Table 6 Experimentally acquired data for Enthalpy and melting/solidification temperature characterization of pure paraffin wax and hybrid PCM/Graphene-Silver (PCM/Gr-Ag) nanocomposites

\begin{tabular}{ccccc}
\hline Samples & \multicolumn{2}{c|}{ Melting process } & \multicolumn{2}{c}{ Solidifying process } \\
\cline { 2 - 5 } & $\begin{array}{c}\text { Latent heat of } \\
\text { melting }\left(\mathrm{J} \mathrm{g}^{-1}\right)\end{array}$ & $\begin{array}{c}\text { Melting } \\
\text { temperature } \\
\left({ }^{\circ} \mathrm{C}\right)\end{array}$ & $\begin{array}{c}\text { Latent heat of } \\
\text { solidifying }\left(\mathrm{J} \mathrm{g}^{-1}\right)\end{array}$ & $\begin{array}{c}\text { Solidification } \\
\text { temperature }\left({ }^{\circ} \mathrm{C}\right)\end{array}$ \\
\hline $\begin{array}{c}\text { Pure paraffin } \\
\text { wax }\end{array}$ & $\sim 110.7$ & 69.8 & $\sim 90.6$ & 50.4 \\
\hline $\begin{array}{c}\text { Hybrid } \\
\text { PCM/Gr-Ag(0.1 } \\
\text { mass\% })\end{array}$ & $\sim 75.6$ & 72.2 & $\sim 71.7$ & 52.3 \\
\hline $\begin{array}{c}\text { Hybrid } \\
\text { PCM/Gr-Ag(0.2 } \\
\text { mass\% })\end{array}$ & $\sim 78.2$ & 73.1 & $\sim 74.3$ & 53.1 \\
\hline $\begin{array}{c}\text { Hybrid } \\
\text { PCM/Gr-Ag(0.3 } \\
\text { mass\% })\end{array}$ & $\sim 88.8$ & 73.2 & $\sim 84.2$ & 53.4 \\
\hline
\end{tabular}

\subsection{Thermal stability of PCM and Nano-PCM}

Thermal durability of the pure organic PCM (PW70) and hybrid PCM/Graphene-Silver nanocomposites is investigated through TGA analysis. Attained TGA curves of mass loss of the pure PCM (PW70) and hybrid PCM/Graphene-Silver nanocomposite samples with the temperature are illustrated in Fig. 6. 


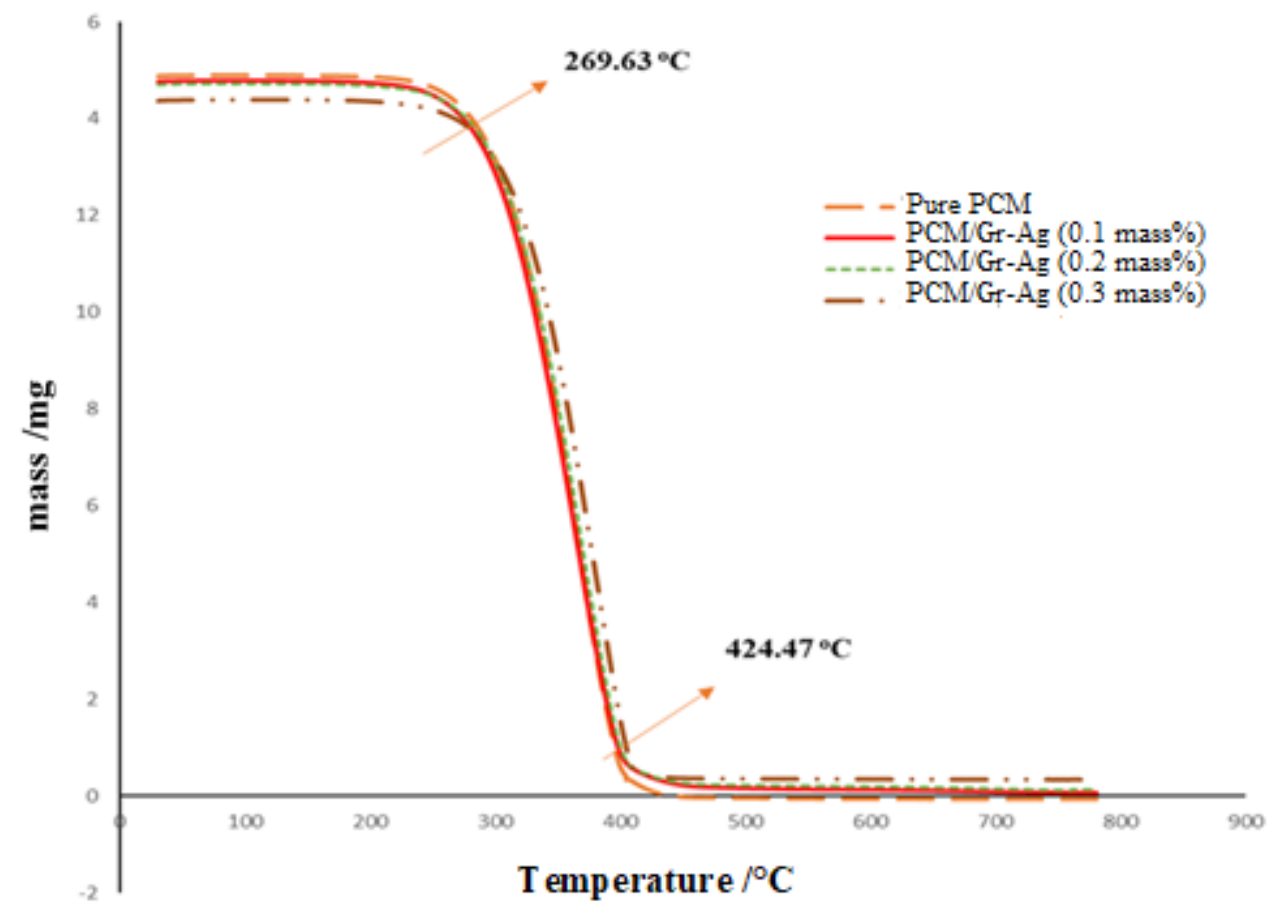

Fig. 6 TG curve of pure organic PCM (PW70) and hybrid PCM/Graphene-Silver (PCM/Gr-Ag) nanocomposites

A unique protocol with the initial mass of $\sim 15 \mathrm{mg}$ and heating rate of $10{ }^{\circ} \mathrm{C} \mathrm{min}^{-1}$ is maintained for the acquisition of data for all samples. It is seen that pure PCM (PW70) shows the mass loss behavior between the temperature 263 and $424{ }^{\circ} \mathrm{C}$. About $70 \%$ mass of PW70 is lost from 263 to $700{ }^{\circ} \mathrm{C}$. It matches with the similar behavior of PCM evaluated by Tang et al. [63]. Due to the low loading of hybrid Graphene-Silver nanomaterial in the PCM, nanocomposite mass loss does not influence much and decomposition phenomenon are mostly act as pure PCM. If the loading of hybrid Graphene-Silver nanomaterial is reached higher such as minimum of $10 \mathrm{mg}$, then it can affect the thermal stability of PCM [64]. There is no degradation of hybrid Graphene-Silver nanomaterial due to the increase of temperature within the range of 30 to $800{ }^{\circ} \mathrm{C}$. Within this temperature range, the hybrid Graphene-Silver nanomaterial possessed negligible mass loss due to the rising temperature [65]. Pure PCM is stable until its decomposition. The decomposition of PCM in this temperature range takes place in microcapsules and components. The microcapsules degradation occurs in a more gradual way after the resultant components is decomposed. Perhaps, such a gradual decomposition could become the consequence of a more resistant shell [66]. Hence, it can be said that hybrid PCM/Graphene-Silver nanocomposite samples have the ability to possess 
very good thermal stability when the temperature is below $263{ }^{\circ} \mathrm{C}$. This property is desirable for a material to be used in thermal storage applications [63].

\subsection{Thermal reliability}

The developed hybrid PCM/Graphene-Silver nanocomposites should stand the long-term application test. Therefore, the thermal reliability of the developed hybrid nanocomposites and pure PCM is determined using a custom designed accelerated thermal cycler. The DSC results are collected at 0,100 and 200 cycles to determine thermal cycling performance of the developed nanocomposites. Table 7, represents the experimentally acquired data for latent heat and melting temperature of pure PCM and developed nanocomposites after 0, 100 and 200 thermal cycles. Pure paraffin wax exhibited $\sim 110.7 \mathrm{~J} \mathrm{~g}^{-1}, \sim 109.8 \mathrm{~J} \mathrm{~g}^{-1}$ and $\sim 109.7 \mathrm{~J} \mathrm{~g}^{-1}$ latent heat storage capacity at 0 , 100 and 200 thermal cycles, respectively. Also, the measured melting temperature of the pure paraffin wax is found to be $69.8{ }^{\circ} \mathrm{C}, 69.5{ }^{\circ} \mathrm{C}$ and $69.6^{\circ} \mathrm{C}$ at 0,100 and 200 thermal cycles, respectively. It is obvious that there is no significant change in the latent heat storage capacity and melting point of the pure PCM, before and after thermal cycling test, which confirms that pure PCM has a good thermal reliability. Similar trend is observed for the developed hybrid PCM/Graphene-Silver nanocomposites with loading concentration of $0.1,0.2$ and 0.3 mass $\%$. Hybrid PCM/Graphene-Silver nanocomposite with loading concentration of 0.1 mass\% showed $\sim 75.6, \sim 75.4$ and $\sim 75.4$ latent heat storage capacity at 0,100 and 200 thermal cycles, respectively. There was negligible difference in the melting temperature of the hybrid nanocomposite with loading concentration of 0.1 mass $\%$ after 200 thermal cycles. The acquired results for the latent heat storage capacity and melting temperature of the hybrid nanocomposite with loading concentration of 0.2 mass $\%$, before and after thermal cycling test showed very low differences of $0.51 \%$ and $0.41 \%$, respectively. Hybrid PCM/Graphene-Silver nanocomposite with loading concentration of 0.3 mass\% represented $\sim 88.8 \mathrm{~J} \mathrm{~g} \mathrm{~g}^{-1}, \sim 88.7 \mathrm{~J} \mathrm{~g}^{-1}$ and $\sim 88.4 \mathrm{~J} \mathrm{~g}^{-1}$ latent heat storage capacity at 0,100 and 200 thermal cycles, respectively. The melting temperature results for the developed hybrid nanocomposite with loading concentration of 0.3 mass $\%$ showed value of 73.2 ${ }^{\circ} \mathrm{C}$ and $72.8^{\circ} \mathrm{C}$ at 0 and 200 thermal cycles, respectively. This long-term performance analysis for the latent heat and melting point of the developed hybrid PCM/Graphene-Silver nanocomposites proves good thermal reliability in proposed applications even after 200 thermal cycles. 
Table 7 Experimentally acquired data for latent heat and melting temperature characterization of pure paraffin wax and hybrid PCM/Graphene-Silver (PCM/Gr-Ag) nanocomposites after 0, 100 and 200 thermal cycles

\begin{tabular}{|c|c|c|c|c|c|c|}
\hline \multirow[t]{3}{*}{ Samples } & \multicolumn{3}{|c|}{ Latent heat $\left(\mathrm{J} \mathrm{g}^{-1}\right)$} & \multicolumn{3}{|c|}{ Melting temperature $\left({ }^{\circ} \mathrm{C}\right)$} \\
\hline & \multicolumn{3}{|c|}{ Thermal cycle } & \multicolumn{3}{|c|}{ Thermal cycle } \\
\hline & 0 & 100 & 200 & 0 & 100 & 200 \\
\hline $\begin{array}{c}\text { Pure paraffin } \\
\text { wax }\end{array}$ & $\sim 110.7$ & $\sim 109.8$ & $\sim 109.7$ & 69.8 & 69.5 & 69.6 \\
\hline $\begin{array}{c}\text { Hybrid } \\
\text { PCM/Gr-Ag(0.1 } \\
\text { mass\%) }\end{array}$ & $\sim 75.6$ & $\sim 75.4$ & $\sim 75.4$ & 72.2 & 71.9 & 71.8 \\
\hline $\begin{array}{c}\text { Hybrid } \\
\text { PCM/Gr-Ag(0.2 } \\
\text { mass } \%) \\
\end{array}$ & $\sim 78.2$ & $\sim 77.6$ & $\sim 77.8$ & 73.1 & 72.7 & 72.8 \\
\hline $\begin{array}{c}\text { Hybrid } \\
\text { PCM/Gr-Ag(0.3 } \\
\text { mass } \%)\end{array}$ & $\sim 88.8$ & $\sim 88.7$ & $\sim 88.4$ & 73.2 & 73 & 72.8 \\
\hline
\end{tabular}

\subsection{Application in the PV/T system}

The governing energy equations and the performance equations, Eq. 1 to Eq. 13, in the methodology are solved simultaneously to evaluate the average PV temperature, the temperature gain across the cooling fluid and the electrical and thermal efficiencies of the CPV/T system with hybrid PCM/Graphene-Silver nanocomposite layer. The performance for the four cases of pure PCM and hybrid PCM/Graphene-silver nanocomposites (0.1,0.2 and 0.3 mass\%) is evaluated and represented in Fig. 7 and Fig. 8. Fig. 7 (a) shows the average temperature of the PV panel during the study time. Higher PV temperature is achieved due to the operation of the system under two implemented solar concentrators. Clearly, it is observed that using the hybrid Graphene-silver nanoparticles resulted in an increase in the cooling capability of the PCM. Increasing the nanoparticles loading reduces PV panel temperature. In comparison to the pure PCM, hybid Graphene-silver nanoparticles at loading concentration of 0.2 mass\%, the average temperature of the PV panel has decreased by $1.9 \%$, while it has decreased by $2.7 \%$ at nanoparticles loading concentration of 0.3 mass $\%$. Fig. 7 (b) shows the enhancement in the temperature gain across the cooling fluid using the nanocomposite samples. The figure reports the enhancement after 3 hours of operation. Introducing the hybrid Graphene-silver nanoparticles to the PCM showed more 
temperature gained by the cooling fluid, and more temperature gain is attained at higher nanoparticles loading. It should be mentioned that higher temperature difference is noticed between the PV temperature and outlet cooling fluid, which can be attributed to the operation of the system under high solar concentration and low cooling fluid and mass flow rate. In the studied case, the temperature gain across the cooling fluid is barely enough to provide some heat for daily water use.

(a)

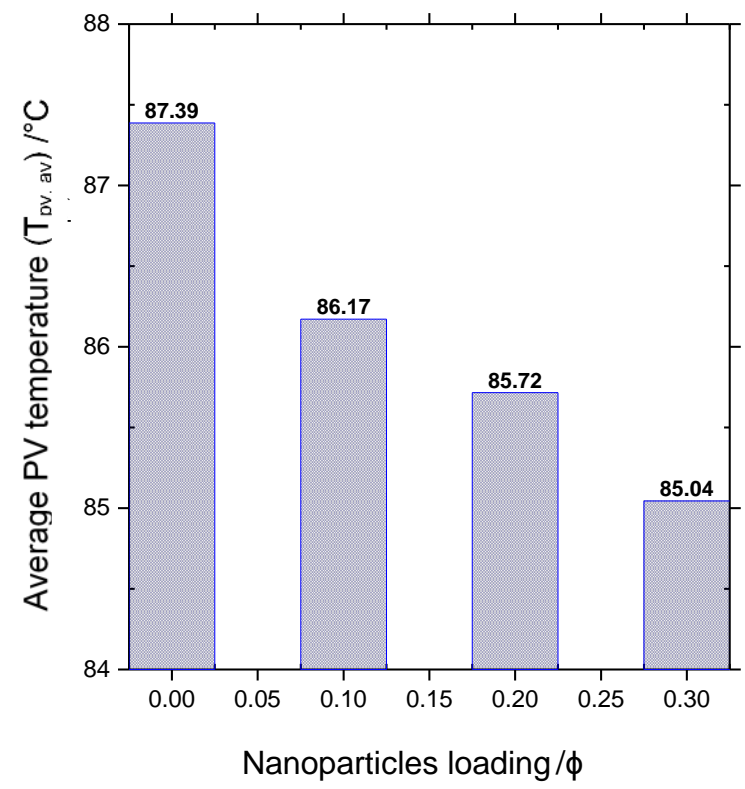

(b)

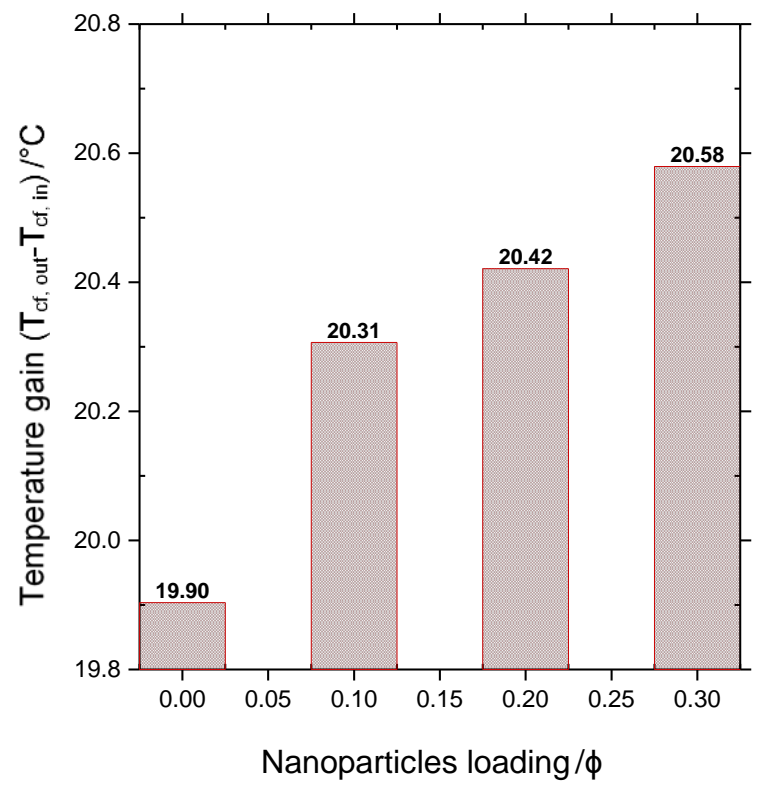

Fig. 7 The effect of the nanomaterial and the nanoparticles' loading on the average temperature of the PV panel and the temperature gain across the cooling fluid for a hybrid CPV/T system with hybrid PCM/Graphene-Silver nanocomposite layer

Fig. 8, shows the electrical and thermal efficiencies of the CPV/T system. The highest values for the electrical efficiency of the system is found at the higher loading concentration of the hybid Graphene-silver nanoparticles as illustrated in Fig. 8 (a). At nanoparticles loading concentration of 0.3 mass \%, the electrical efficiency is improved by $1.33 \%$ in comparison to the pure PCM. Fig. 8 (b), shows different shape for the thermal performance of the CPV/T system. The highest thermal efficiency using the hybrid Graphene-silver nanoparticles is reported at nanoparticles loading concentration of 0.2 mass\%. In addition, it is observed that the hybrid PCM/GrapheneSilver nanocomposites, at nanoparticles loading concentration of 0.1 mass $\%$ and 0.3 mass $\%$, 
show slightly lower thermal efficiency than its value at nanoparticles loading concentration of 0.2 mass \%. The difference in the thermal efficiency results is attributed to its dependence on the energy passed through the pure PCM/hybrid nano-PCM to the cooling fluid channel during the study time, which is directly dependent on the thermal properties of the pure PCM/hybrid nanoPCM samples. As the study has been extended to 3 hours and the average PV temperature exceeded the melting temperature of the samples, different thermal behaviors are expected from the system at different pure PCM/hybrid nano-PCM samples due to the different sensible and latent thermal properties.

(a)

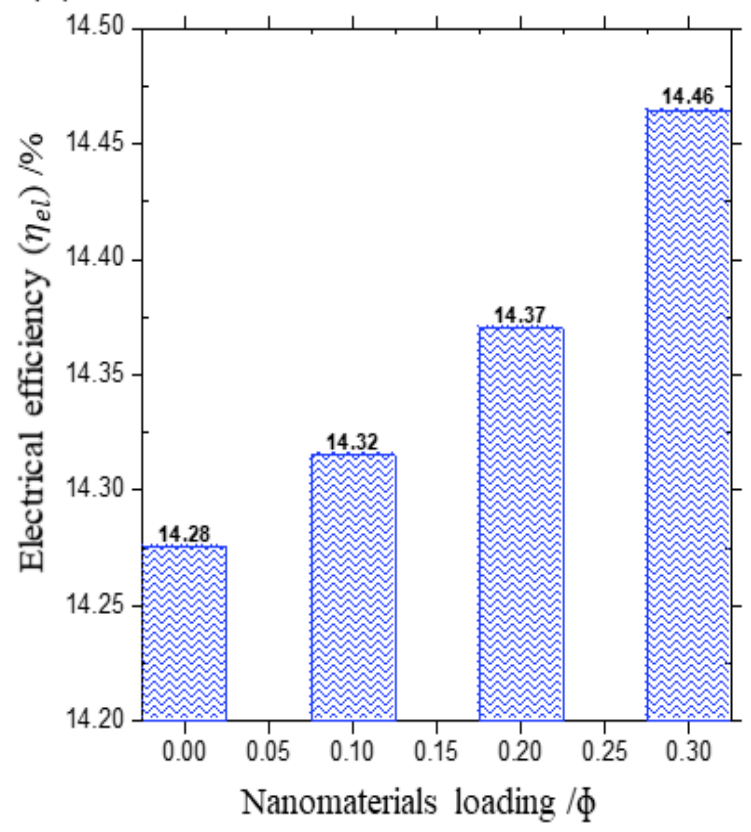

(b)

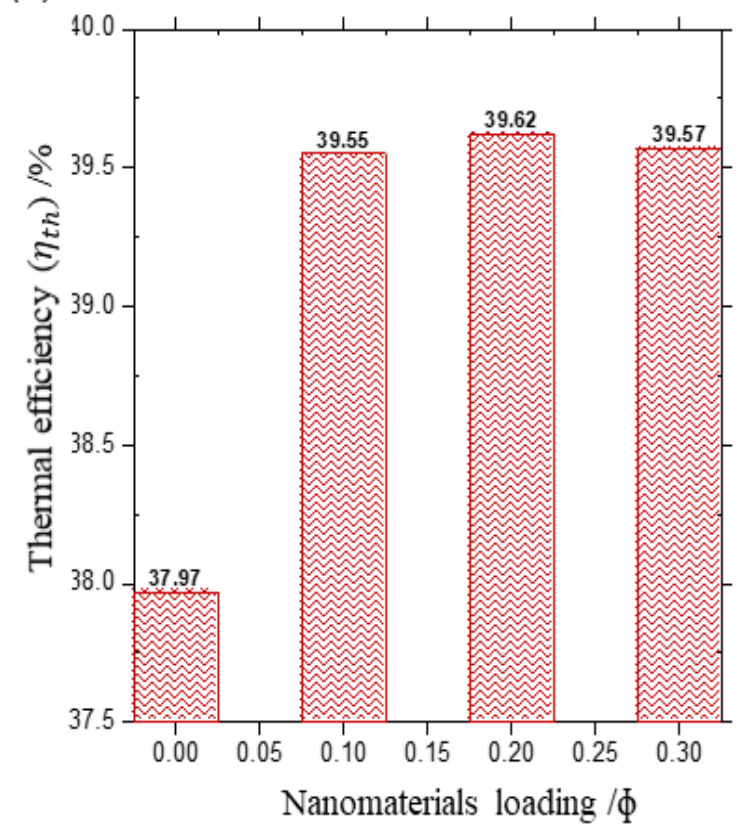

Fig. 8 The effect of the nanomaterial and the nanoparticles' loading on the electrical and thermal efficiencies of the PV panel for a hybrid CPV/T system with hybrid PCM/Graphene-Silver nanocomposite layer

Assuming that the thermal energy can be converted into electrical energy using a ThermoElectric Generator (TEG) with conversion efficiency of $40 \%$, as for the gas and combined plants [34], the equivalent electrical efficiency of the CPV/T system using PCM and the hybrid PCM/Graphene-Silver nanocomposite ( 0.1 mass $\%, 0.2$ mass $\%$ and 0.3 mass $\%$ ) samples was 
evaluated as:

$$
\eta_{e l, e q}=\eta_{e l}+0.4 \times \eta_{t h}
$$

The results of the equivalent electrical efficiency were depicted in Fig. 9.

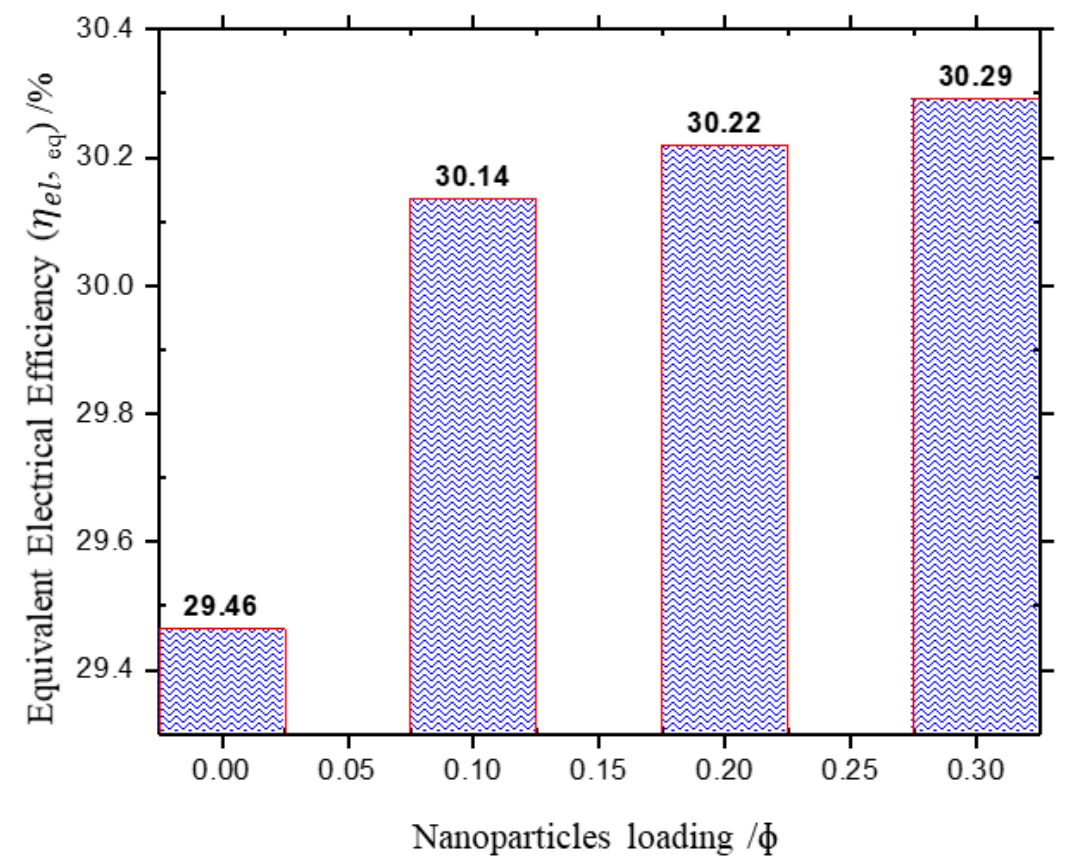

Fig. 9 The effect of the nanomaterial and the nanoparticles' loading on the equivalent electrical efficiency of the PV panel for a hybrid CPV/T system with hybrid PCM/Graphene-Silver nanocomposite layer

From Fig. 9, it is revealed that the equivalent electrical performance of the CPV/T system has been enhanced with the increase of the nanoparticles loading. The rate of increase of the equivalent electrical efficiency is small. In comparison to the pure PCM, the equivalent electrical performance is improved by $2.3 \%, 2.6 \%$ and $2.8 \%$ at hybrid Graphene-silver nanoparticles loading concentration of $0.1,0.2$ and 0.3 mass $\%$, respectively. To sum up, the addition of the hybrid Graphene-silver nanoparticles to the PCM enhances the performance of the CPV/T system and lower PV temperatures. Moreover, higher temperature gains across the cooling fluid and higher electrical and thermal efficiencies are achieved. Increasing the nanoparticles loading, the cooling of the PV panel is improved, which cause to increase the temperature gain across the cooling fluid and the electrical efficiency of the CPV/T system. The thermal efficiency is mainly dependent on 
the temperature gain across the cooling fluid, the thermal properties of the hybrid PCM/GrapheneSilver nanocomposites and the study period for the system. Better cooling for the PV panel and more temperature gain across the cooling fluid are expected at higher nanoparticles concentration. In addition, changing the thickness of the hybrid PCM/Graphene-Silver nanocomposite layer and the mass flow rate of the cooling fluid may result in lower temperatures for the PV panel and higher values for the electrical and thermal efficiencies of the CPV/T system, which can be recommended as for future studies.

\section{Conclusion}

In this paper, a new class of nanocomposites using hybrid Graphene-Silver nanoparticles as additive to a pure organic phase change material is synthesized successfully. Chemical structure analysis showed good formation of the synthesized nanocomposites. Thermal energy storage capability of the hybrid PCM/Graphene-Silver nanocomposites and pure paraffin wax is measured in the temperature range of $25-250{ }^{\circ} \mathrm{C}$ considering decomposition temperature as maximum operation temperature. It is evidenced that the hybrid PCM/Graphene-Silver nanocomposites with mass fraction of 0.3 mass\% shows highest improvement of specific heat capacity of the hybrid PCM/Graphene-Silver nanocomposite by $\sim 40 \%$. Thermal conductivity of the hybrid PCM/Graphene-Silver nanocomposite is found to have enhancement of $\sim 11 \%$ with mass fraction of 0.3 mass \%. The unique two-dimensional and well-formed layers of planar structure of hybrid Graphene-Silver nanomaterial (represented in section 3.1.) leads to obtain highly promising thermo-physical properties. The melting point of the synthesized nanocomposite is shown to be slightly increased at higher loadings of hybrid Graphene-Silver nanomaterial. The melting point for pure paraffin is found to be $69.8{ }^{\circ} \mathrm{C}$. Melting point of hybrid PCM/Graphene-Silver nanocomposite with loading concentration of 0.3 mass $\%$ is measured to be $73.2^{\circ} \mathrm{C}$. It is observed from the DSC curves that the endothermic enthalpy value decreases with hybrid Graphene-Silver nanomaterial as additive. The measured enthalpy values for the pure paraffin wax is $\sim 110.7 \mathrm{~J} \mathrm{~g}^{-1}$. DSC measurement for the enthalpy of the hybrid PCM/Graphene-Silver nanocomposites with the concentrations of $0.1,0.2$ and 0.3 mass\% represented values of $\sim 75.6, \sim 78.2$ and $\sim 88.8 \mathrm{~J} \mathrm{~g}^{-1}$. This indicates the release of energy in melting and heat transfer is enhanced in this crucial point. Thermal durability measurements revealed that the mass loss occurs within the temperature range from 263 to $424{ }^{\circ} \mathrm{C}$. The long-term performance analysis for the latent heat and melting point of 
the developed hybrid PCM/Graphene-Silver nanocomposites proved good thermal reliability in proposed applications even after 200 thermal cycles. Addition of the hybrid Graphene-silver nanoparticles to the PCM represented the capability of enhancement in the performance of the $\mathrm{CPV} / \mathrm{T}$ system and lower PV temperatures, higher temperature gains across the cooling fluid and higher electrical and thermal efficiencies. At nanoparticles loading concentration of 0.3 mass $\%$, the electrical efficiency is improved by $1.33 \%$ in comparison with the pure PCM. The highest thermal efficiency using the hybrid Graphene-silver nanoparticles reached the value of $39.62 \%$ which represents $4.16 \%$ increment in comparison with the pure PCM. Upon realizing the superior performance of the hybrid Graphene-Silver nanomaterial in serving as nanofillers for preparation of PCM nanocomposites with enhanced thermal storage and thermal conductivity, the effects of the number of layers, thickness and the size analysis are of great interest for future studies. Thermal conductivity at higher temperatures also need to be carried to investigate its variation with temperature.

\section{Acknowledgements}

"R. Saidur would like to acknowledge the financial support provided by the Sunway University through the project no\# STR-RCTR-RCNMET-001-2019".

\section{References}

1. Hesaraki A. CFD modeling of heat charging process in a direct-contact container for mobilized thermal energy storage. LAP LAMBERT Academic Publishing; 2011.

2. Raul A, Jain M, Gaikwad S, Saha SKJATE. Modelling and experimental study of latent heat thermal energy storage with encapsulated PCMs for solar thermal applications. Appl Therm Eng. 2018;143:415-28.

3. Li D, Wang J, Ding Y, Yao H, Huang YJAE. Dynamic thermal management for industrial waste heat recovery based on phase change material thermal storage. Appl Energy. 2019;236:1168-82.

4. Ali HM, Arshad A, Jabbal M, Verdin PGJIJoH, Transfer M. Thermal management of electronics devices with PCMs filled pin-fin heat sinks: a comparison. Int J Heat Mass Transf. 2018;117:1199-204.

5. Sharma A, Tyagi W, Chen C, Buddhi D. Review on thermal energy storage with phase change materials and applications. Renew Sust Energ Rev. 2009;13(2):318-45.

6. Kenisarin M, Mahkamov K, Kahwash F, Makhkamova IJSEM, Cells S. Enhancing thermal conductivity of paraffin wax $53-57^{\circ} \mathrm{C}$ using expanded graphite. Sol Energy Mater Sol Cells. 2019;200:110026.

7. Radhakrishnan N, Thomas S, Sobhan C. Characterization of thermophysical properties of nanoenhanced organic phase change materials using T-history method. J Therm Anal Calorim. 2019;140:247184. 
8. Jegadheeswaran S, Sundaramahalingam A, Pohekar SD. High-conductivity nanomaterials for enhancing thermal performance of latent heat thermal energy storage systems. J Therm Anal Calorim. 2019;138(2):1137-66.

9. Aslfattahi N, Saidur R, Arifutzzaman A, Sadri R, Bimbo N, Sabri MFM et al. Experimental investigation of energy storage properties and thermal conductivity of a novel organic phase change material/MXene as A new class of nanocomposites. J Energy Storage. 2020;27:101115.

10. Lafdi K, Mesalhy O, Shaikh S. Experimental study on the influence of foam porosity and pore size on the melting of phase change materials. J Appl Phys. 2007;102(8):083549.

11. Yordanov GG, Adachi E, Dushkin CD. Characterization of CdS nanoparticles during their growth in paraffin hot-matrix. Mater charact. 2007;58(3):267-74.

12. Zhao L, Li Y, Cao X, You J, Dong WJN. Multifunctional role of an ionic liquid in melt-blended poly (methyl methacrylate)/multi-walled carbon nanotube nanocomposites. Nanotechnology. 2012;23(25):255702.

13. Zhao Y, Min X, Huang Z, Liu Yg, Wu X, Fang MJE et al. Honeycomb-like structured biological porous carbon encapsulating PEG: A shape-stable phase change material with enhanced thermal conductivity for thermal energy storage. Energy Build. 2018;158:1049-62.

14. Zhao Y, Sun B, Du P, Min X, Huang Z, Liu Yg et al. Hierarchically channel-guided porous wood-derived shape-stabilized thermal regulated materials with enhanced thermal conductivity for thermal energy storage. Mater Res Express. 2019;6(11):115515.

15. Chaichan MT, Kamel SH, Al-Ajeely A. Thermal conductivity enhancement by using nano-material in phase change material for latent heat thermal energy storage systems. Saussurea. 2015;5(6):48-55.

16. Sarı A, Karaipekli A. Thermal conductivity and latent heat thermal energy storage characteristics of paraffin/expanded graphite composite as phase change material. Appl Therm Eng. 2007;27(8-9):1271-7.

17. Wei S, Duan Z, Xia Y, Huang C, Ji R, Zhang $\mathrm{H}$ et al. Preparation and thermal performances of microencapsulated phase change materials with a nano-Al 20 3-doped shell. J Therm Anal Calorim. 2019;138(1):233-41.

18. Kazemi M, Kianifar A, Niazmand $\mathrm{H}$. Nanoparticle loading effect on the performance of the paraffin thermal energy storage material for building applications. J Therm Anal Calorim. 2020;139(6):3769-75.

19. Meng $X$, Zhang H, Sun L, Xu F, Jiao $Q$, Zhao Z et al. Preparation and thermal properties of fatty acids/CNTs composite as shape-stabilized phase change materials. J Therm Anal Calorim. 2013;111(1):377-84.

20. Wu S, Ma X, Peng D, Bi YJJoTA, Calorimetry. The phase change property of lauric acid confined in carbon nanotubes as nano-encapsulated phase change materials. J Therm Anal Calorim. 2019;136(6):2353-61.

21. Temel UN, Kurtulus S, Parlak M, Yapici KJJoTA, Calorimetry. Size-dependent thermal properties of multi-walled carbon nanotubes embedded in phase change materials. J Therm Anal Calorim. 2018;132(1):631-41.

22. Zhong Y, Guo Q, Li S, Shi J, Liu L. Heat transfer enhancement of paraffin wax using graphite foam for thermal energy storage. Sol Energy Mater Sol Cells. 2010;94(6):1011-4.

23. Min X, Fang M, Huang Z, Liu Yg, Huang Y, Wen R et al. Enhanced thermal properties of novel shapestabilized PEG composite phase change materials with radial mesoporous silica sphere for thermal energy storage. Sci Rep. 2015;5:12964.

24. Ranjbar S, Masoumi H, Khoshkhoo RH, Mirfendereski M. Experimental investigation of stability and thermal conductivity of phase change materials containing pristine and functionalized multi-walled carbon nanotubes. J Therm Anal Calorim. 2019;140:2505-18.

25. Yarmand H, Gharehkhani S, Ahmadi G, Shirazi SFS, Baradaran S, Montazer E et al. Graphene nanoplatelets-silver hybrid nanofluids for enhanced heat transfer. Energy convers manag. 2015;100:41928. 
26. Shagor RMR. Effects of graphene functionalization on mechanical properties of carbon fiber laminate composites: Wichita State University; 2015.

27. Sharma A, Shukla A, Chen C, Wu T-N. Development of phase change materials (PCMs) for low temperature energy storage applications. Sustain Energy Technol Assess. 2014;7:17-21.

28. Li M, Zhang Z, Gao H, Wang Y, Liang J, Shu D et al. Formation of multilayer interfaces and the load transfer in graphene nanoplatelets reinforced Al matrix composites. Mater Charact. 2019;159:110018.

29. Lau D, Song N, Hall C, Jiang Y, Lim S, Perez-Wurfl I et al. Hybrid solar energy harvesting and storage devices: the promises and challenges. Mater Today Energy. 2019;13:22-44.

30. Lugolole R, Mawire A, Okello D, Lentswe KA, Nyeinga K, Shobo AB. Experimental analyses of sensible heat thermal energy storage systems during discharging. Sustain Energy Technol Assess. 2019;35:117130.

31. Mendoza-Lopez M, Pérez-Bueno J, Rodriguez-Garcia M. Characterizations of silver alloys used in modern Mexican coins. Mater Charact. 2009;60(9):1041-8.

32. Vargas-Ordaz M, Velázquez-Hernández I, Bañuelos JA, Ledesma-García J, Álvarez-Contreras L, Arjona $\mathrm{N}$ et al. Synthesis of PtAg bimetallic material as a multi-fuel tolerant electrocatalyst and spectroelectrochemical analysis of its capability to perform the oxygen reduction. Mater Today Energy. 2019;14:100335.

33. Kishore M, Rao YH. Green synthesis and characterization of silver nanoparticle from ampelocissus latifolia root extract. Mater Today: Proceedings. 2018;5(13):26271-9.

34. Fan $\mathrm{H}$, Singh $\mathrm{R}$, Akbarzadeh A. Electric power generation from thermoelectric cells using a solar dish concentrator. J electron mater. 2011;40(5):1311-20.

35. Jana S, Salehi-Khojin A, Zhong W-H. Enhancement of fluid thermal conductivity by the addition of single and hybrid nano-additives. Thermochim acta. 2007;462(1-2):45-55.

36. Abdulateef J, Ali SD, Mahdi MS. Thermodynamic Analysis of Solar Absorption Cooling System. Journal of Advanced Research in Fluid Mechanics and Thermal Sciences. 2019;60(2):233-46.

37. Tafrishi H, Sadeghzadeh S, Molaei F, Siavoshi H. Investigating the effects of adding hybrid nanoparticles, graphene and boron nitride nanosheets, to octadecane on its thermal properties. RSC Adv. 2020;10(25):14785-93.

38. Ghalambaz M, Doostani A, Chamkha AJ, Ismael MAJIJoMS. Melting of nanoparticles-enhanced phasechange materials in an enclosure: effect of hybrid nanoparticles. Int J Mech Sci. 2017;134:85-97.

39. Phase Change Materials Products Ltd Company 2011.

40. US Research Nanomaterials, Inc. 2016.

41. Wang S, Wang C, Ji X. Towards understanding the salt-intercalation exfoliation of graphite into graphene. RSC Adv. 2017;7(82):52252-60.

42. Ramesh BP, Blau W, Tyagi P, Misra D, Ali N, Gracio J et al. Thermogravimetric analysis of cobalt-filled carbon nanotubes deposited by chemical vapour deposition. Thin Solid Films. 2006;494(1-2):128-32.

43. Cheng C, Li D. Solvated graphenes: an emerging class of functional soft materials. Adv Mater. 2013;25(1):13-30.

44. Khanam PN, Ponnamma D, Al-Madeed M. Electrical properties of graphene polymer nanocomposites. Graphene-based polymer nanocomposites in electronics. Springer; 2015. p. 25-47.

45. Kotia A, Haldar A, Kumar R, Deval P, Ghosh SK. Effect of copper oxide nanoparticles on thermophysical properties of hydraulic oil-based nanolubricants. Journal of the Brazilian Society of Mechanical Sciences and Engineering. 2017;39(1):259-66.

46. Abed MS, Abed AS, Othman FM. Green Synthesis of Silver Nanoparticles from Natural Compounds: Glucose, Eugenol and Thymol. Journal of Advanced Research in Fluid Mechanics and Thermal Sciences. 2019;60(1):95-111.

47. Johnson LM, Gao L, Shields IV CW, Smith M, Efimenko K, Cushing K et al. Elastomeric microparticles for acoustic mediated bioseparations. J nanobiotechnology. 2013;11(1):22. 
48. Allahyarzadeh $\mathrm{V}$, Montazer $\mathrm{M}$, Nejad NH, Samadi N. In situ synthesis of nano silver on polyester using $\mathrm{NaOH} / \mathrm{Nano}$ TiO2. J Appl Polym Sci. 2013;129(2):892-900.

49. Fallahi E, Barmar M, Kish MH. Preparation of phase-change material microcapsules with paraffin or camel fat cores: application to fabrics. Iran polym J. 2010;19(4):277-86.

50. Kim CH, Joo C-K, Chun HJ, Yoo BR, Noh DI, Shim YB. Instrumental studies on silicone oil a dsorption to the surface of intraocular lenses. Appl Surf Sci. 2012;262:146-52.

51. Mansur HS, Oréfice RL, Mansur AA. Characterization of poly (vinyl alcohol)/poly (ethylene glycol) hydrogels and PVA-derived hybrids by small-angle X-ray scattering and FTIR spectroscopy. Polymer. 2004;45(21):7193-202.

52. Wang X-Q, Mujumdar AS, Yap C. Effect of orientation for phase change material (PCM)-based heat sinks for transient thermal management of electric components. Int Commun Heat Mass Transf. 2007;34(7):801-8.

53. Wang J, Xie H, Xin Z. Thermal properties of paraffin based composites containing multi-walled carbon nanotubes. Thermochim Acta. 2009;488(1-2):39-42.

54. Balandin AA, Ghosh S, Bao W, Calizo I, Teweldebrhan D, Miao F et al. Superior thermal conductivity of single-layer graphene. Nano lett. 2008;8(3):902-7.

55. Shahil KM, Balandin AA. Graphene-multilayer graphene nanocomposites as highly efficient thermal interface materials. Nano lett. 2012;12(2):861-7.

56. Gu J, Xie C, Li H, Dang J, Geng W, Zhang Q. Thermal percolation behavior of graphene nanoplatelets/polyphenylene sulfide thermal conductivity composites. Polym Compos. 2014;35(6):10871092.

57. Baby TT, Ramaprabhu S. Investigation of thermal and electrical conductivity of graphene based nanofluids. J Appl Phys. 2010;108(12):124308.

58. Warzoha RJ, Fleischer AS. Heat flow at nanoparticle interfaces. Nano Energy. 2014;6:137-58.

59. Pfleger N, Bauer T, Martin C, Eck M, Wörner A. Thermal energy storage-overview and specific insight into nitrate salts for sensible and latent heat storage. Beilstein J Nanotechnol. 2015;6(1):1487-97.

60. Babaei $H$, Keblinski $P$, Khodadadi J. Thermal conductivity enhancement of paraffins by increasing the alignment of molecules through adding CNT/graphene. Int J Heat Mass Transf. 2013;58(1-2):209-16.

61. Dinker A, Agarwal M, Agarwal G. Heat storage materials, geometry and applications: A review. J Energy Inst. 2017;90(1):1-11.

62. Malik DR. Evaluation of composite alumina nanoparticle and nitrate eutectic materials for use in concentrating solar power plants: Texas A \& M University; 2010.

63. Tang B, Qiu M, Zhang S. Thermal conductivity enhancement of PEG/SiO2 composite PCM by in situ Cu doping. Sol Energy Mater Sol Cells. 2012;105:242-8.

64. Gao R, Hu N, Yang Z, Zhu Q, Chai J, Su Y et al. like graphene-Ag composite films with enhanced mechanical and electrical properties. Nanoscale Res Lett. 2013;8(1):32.

65. Shen J, Shi M, Yan B, Ma H, Li N, Ye M. One-pot hydrothermal synthesis of Ag-reduced graphene oxide composite with ionic liquid. J Mater Chem. 2011;21(21):7795-801.

66. Bayés-García L, Ventola L, Cordobilla R, Benages R, Calvet T, Cuevas-Diarte M. Phase change materials (PCM) microcapsules with different shell compositions: preparation, characterization and thermal stability. Sol Energy Mater Sol Cells. 2010;94(7):1235-40. 